\title{
Comprehensive genotyping of the USA national maize inbred seed bank
}

\author{
Maria C Romay ${ }^{1}$, Mark J Millard ${ }^{2,3}$, Jeffrey C Glaubitz', Jason A Peiffer ${ }^{4}$, Kelly L Swarts ${ }^{5}$, Terry M Casstevens ${ }^{1}$, \\ Robert J Elshire', Charlotte B Acharya', Sharon E Mitchell', Sherry A Flint-Garcia ${ }^{2,6}$, Michael D McMullen, \\ James B Holland ${ }^{2,7}$, Edward S Buckler ${ }^{1,2,5^{*}}$ and Candice A Gardner ${ }^{2,3^{*}}$
}

\begin{abstract}
Background: Genotyping by sequencing, a new low-cost, high-throughput sequencing technology was used to genotype 2,815 maize inbred accessions, preserved mostly at the National Plant Germplasm System in the USA. The collection includes inbred lines from breeding programs all over the world.

Results: The method produced 681,257 single-nucleotide polymorphism (SNP) markers distributed across the entire genome, with the ability to detect rare alleles at high confidence levels. More than half of the SNPs in the collection are rare. Although most rare alleles have been incorporated into public temperate breeding programs, only a modest amount of the available diversity is present in the commercial germplasm. Analysis of genetic distances shows population stratification, including a small number of large clusters centered on key lines. Nevertheless, an average fixation index of 0.06 indicates moderate differentiation between the three major maize subpopulations. Linkage disequilibrium (LD) decays very rapidly, but the extent of LD is highly dependent on the particular group of germplasm and region of the genome. The utility of these data for performing genome-wide association studies was tested with two simply inherited traits and one complex trait. We identified trait associations at SNPs very close to known candidate genes for kernel color, sweet corn, and flowering time; however, results suggest that more SNPs are needed to better explore the genetic architecture of complex traits.

Conclusions: The genotypic information described here allows this publicly available panel to be exploited by researchers facing the challenges of sustainable agriculture through better knowledge of the nature of genetic diversity.
\end{abstract}

Keywords: Diversity, Genotyping by sequencing, Germplasm, Maize, Public

\section{Background}

Maize (Zea mays L.) is one of the most important crops in the world, being one of the main sources of human food, animal feed, and raw material for some industrial processes [1].Furthermore, maize is a significant model plant for the scientific community to study phenomena such as hybrid vigor, genome evolution, and many other important biological processes. The maize genome is complex, and has a very high level of genetic diversity compared with other crops and model plant species [2].

\footnotetext{
*Correspondence: esb33@cornell.edu; Candice.Gardner@ARS.USDA.GOV 'Institute for Genomic Diversity, Biotechnology bldg., Cornell University, Ithaca, NY, 14853, USA

USA Department of Agriculture (USDA) - Agricultural Research Service (USDA-ARS

Full list of author information is available at the end of the article
}

The Zea genome is in constant flux, with transposable elements changing the genome and affecting genetic diversity [3]. Structural variations between any two maize plants are prevalent and are enriched relative to single-nucleotide polymorphism (SNP) markers as significant loci associated with important phenotypic traits [4]. The availability of new sequencing technologies at increasingly affordable prices has provided the opportunity to investigate more deeply the maize genome and its diversity, enabling genome-wide association studies (GWAS) and genomic selection (GS) strategies.

Since the beginning of the 20th Century, when Shull [5] and East [6] first investigated inbreeding and heterosis in maize, breeding programs around the world have developed maize inbred lines using diverse strategies. 
The USDA-ARS North Central Regional Plant Introduction Station (NCRPIS) in Ames, Iowa, an element of the National Plant Germplasm System, along with germplasm banks around the world, has conserved distinct inbred lines that represent nearly a century of maize breeding efforts. Researchers have genotypically characterized subsets of these maize inbred lines to assist with curatorial management of germplasm collections, to evaluate diversity within breeding programs, and for use in association mapping [7-10]. Some association panels have been used successfully to characterize many different traits, frequently through a candidate gene strategy [11]. However, the sample sizes used in these studies may not have been large enough to detect all of the key quantitative trait loci (QTL) for the complex traits. Furthermore, the nature of population structure in maize may have resulted in further dilution of statistical power and high rates of false discovery [12]. In addition, candidate gene strategies require an understanding of the biochemical or regulatory pathways controlling the traits.

Recently, Elshire et al. [13] developed a simple new sequencing procedure that provides a large number of markers across the genome at low cost per sample. The approach, called genotyping by sequencing (GBS), can be applied to species with high diversity and large genomes such as maize. It does not rely on previous knowledge of SNPs; however, the high-quality reference genome for the maize inbred $B 73$ [14] is used at this point to anchor the position of the SNPs. The method enables characterization of germplasm collections on a genome-wide scale, and greatly expands the number of individuals and markers under study, which then increases the chances of discovering more uncommon or rare variants [15]. In maize, there are examples of important rare alleles unique to some groups of germplasm, such as alleles at $c r t R B 1$ that increase $\beta$-carotene concentrations in kernels [16]. Several studies have also suggested that rare alleles could explain the 'missing heritability' problem. This is the phenomenon by which a large portion of the inferred genetic variance for a trait is often not fully accounted for by the loci detected by GWAS [17]. Moreover, the increased number of samples and markers allow a deeper study of haplotype structures and linkage disequilibrium (LD). Regions with strong LD and large haplotype blocks as a result of reduced recombination make it more difficult to separate genes that can have different effects, affecting both mapping and/or selection of the positive alleles for a trait. This linkage between favorable and negative alleles also contributes to heterosis [18].

In the current study, we used GBS to analyze a total of 4,351 maize samples from 2,815 maize accessions with 681,257 SNP markers distributed across the entire genome. These data allowed us to 1) compare this new sequencing technology with other available options, 2) explore the potential of this new technology to help with curation and use of germplasm, 3) evaluate genetic diversity and population structure both across the genome and between groups of germplasm, 4) investigate the history of recombination and LD through the different breeding groups, and 5) explore the potential of the collection as a resource to study the genetic architecture of quantitative traits.

\section{Results}

\section{Marker coverage and missing data}

The germplasm set examined in this experiment comprised 2,711 available maize inbred accessions preserved in the USDA-ARS NCRPIS collection (some of them with more than one source), another 417 candidates to be incorporated into the USDA collection as new sources of diversity, and the 281 maize inbred lines from the Goodman maize association panel [8]. Most of the accessions were sequenced once, with one representative plant chosen for the DNA extraction, resulting in a single GBS sample. However, for 558 accessions, more than one plant was sequenced so different sources could be compared, and therefore more than one GBS sample was available. Moreover, 326 DNA samples were sequenced multiple times as technical replicates. Thus, the total number of GBS samples analyzed in this study was 4,351 (see Additional file 1). From the complete set of 681,257 SNP markers across all maize lines analyzed to date, we selected 620,279 SNPs that are polymorphic among our samples. These SNPs are distributed along the 10 maize chromosomes, and more highly concentrated in sub-telomeric than pericentromeric regions (Figure 1).

The average base-call error rate based on repeated samples was $0.18 \%$. An additional level of quality control was provided by approximately 7,000 SNPs that overlapped with those obtained with a large genotyping array [19] for the 281 maize inbreds from the Goodman association panel. The mean discrepancy rate between the GBS and array SNP genotypes for all calls was $1.8 \%$. When heterozygote calls are excluded from the comparison, the discrepancy rate decreased to $0.58 \%$.

The average coverage (SNP call rate) by sample was $35 \%$, with values ranging from 2 to $75 \%$. However, when samples were sequenced more than once, coverage improved substantially. For example, the Goodman association panel was evaluated twice, and reduced the average missing data from $63 \%$ based on a single run to $35 \%$ for the merged data. The nested association mapping (NAM) parents [18], covered by seven replicate sequencing runs, was found to have only $23 \%$ missing data. The inbred line SA24, used as a check, was analyzed more than 25 times and had only $16 \%$ missing data. In addition, coverage was 


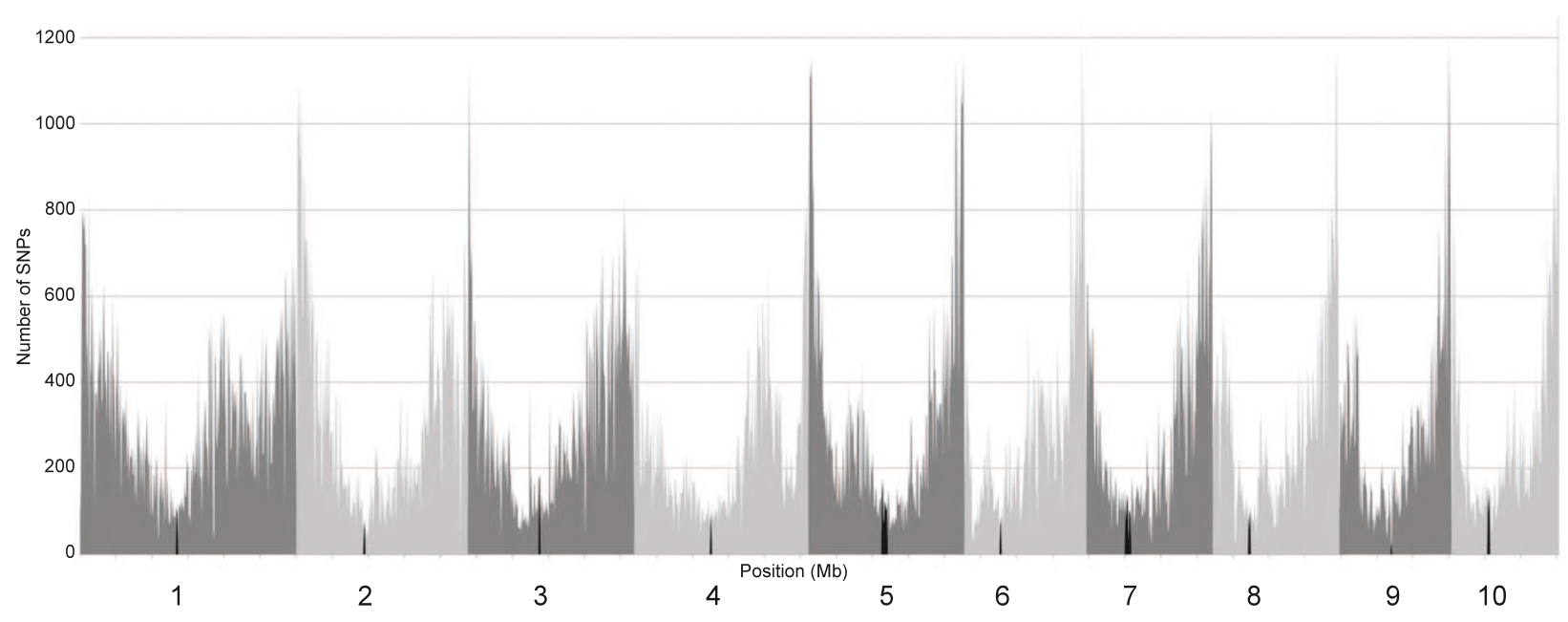

Figure 1 distribution of single-nucleotide polymorphisms (SNPs) across the genome. Distribution of the number of SNPs found in 1 Mb windows across the 10 maize chromosomes. Centromere positions are shown in black.

highly dependent on the genotype. A substantial number of the total reads could not be aligned to the reference genome, some because of limited sensitivity of the Burrows-Wheeler Alignment (BWA) software, but most because of presence/absence variation (PAV). Use of the $B 73$ reference genome resulted in inbreds more closely related to $B 73$ achieving values of less than $20 \%$ missing data with only two samples, whereas more distant inbreds maintained values of around $30 \%$ missing data even after several replicate sequencing runs.

Imputation of missing data was performed using an algorithm that searched for the closest neighbor in small SNP windows across our entire maize database (approximately 22,000 Zea samples), allowing for a 5\% mismatch. If the requirements were not met, the SNP was not imputed, leaving only about $10 \%$ of the data unimputed. When comparing the imputed GBS data with the results from the genotyping array [19] for the 281 maize inbreds from the Goodman association panel, the median discrepancy rate for all calls was $4 \%$. Excluding heterozygote calls, the median error rate was $1.83 \%$. Imputed data were used only to perform GWAS analysis.

\section{Integrity and pedigree relationships of the germplasm collection}

Curatorial management of such an enormous collection of an annual plant is challenging, and various steps of the process may contribute to problems such as errors or material duplications. However, when we calculated the proportion of markers identical by state (IBS) for all pairs of lines (Figure 2A), GBS data showed that more than $98 \%$ of the approximately 2,200 samples that shared an accession name were more than 0.99 IBS even when derived from different inventory samples (Figure 2B).
Most of the mismatches were traced back to problems during the DNA manipulation step. This showed that misclassification or contamination problems are not common in the bank. When more than one sample per accession was available, intra-accession variability was detected (Figure 2B). For those accessions, the IBS value was lower than expected, owing to residual heterozygosity. However, for most of the accessions in this study, only one plant was analyzed, and thus intra-accession variability could not be assayed. Based on our average error rates, we selected 0.99 as a conservative value to assume that two different samples with the same name but different origins are actually the same accession. When more than two samples per accession were available, if IBS values were consistent between all comparisons we considered the differences to be the result of residual heterozygosity. We merged the information from replicated samples that met those criteria to obtain a final list of 2,815 unique maize inbred lines.

Maize inbred development through the world has been accomplished in many different ways, but some of the most common procedures consist of intermating existing elite materials or incorporating a desirable trait from a donor into an elite inbred line through backcross breeding [20]. Thus, we expected that a high number of the inbred lines in our collection would be closely related. Using IBS, we examined the distribution of the IBS relationships (Figure 2A) and the 10 closest neighbors for each unique inbred line (see Additional file 2). The data reflect the continuous exchange and refinement of germplasm that has occurred over the breeding history of maize and the efforts by breeders to introduce new diversity into their programs. We calculated identity by descent (IBD) for all possible pairwise combinations of the 

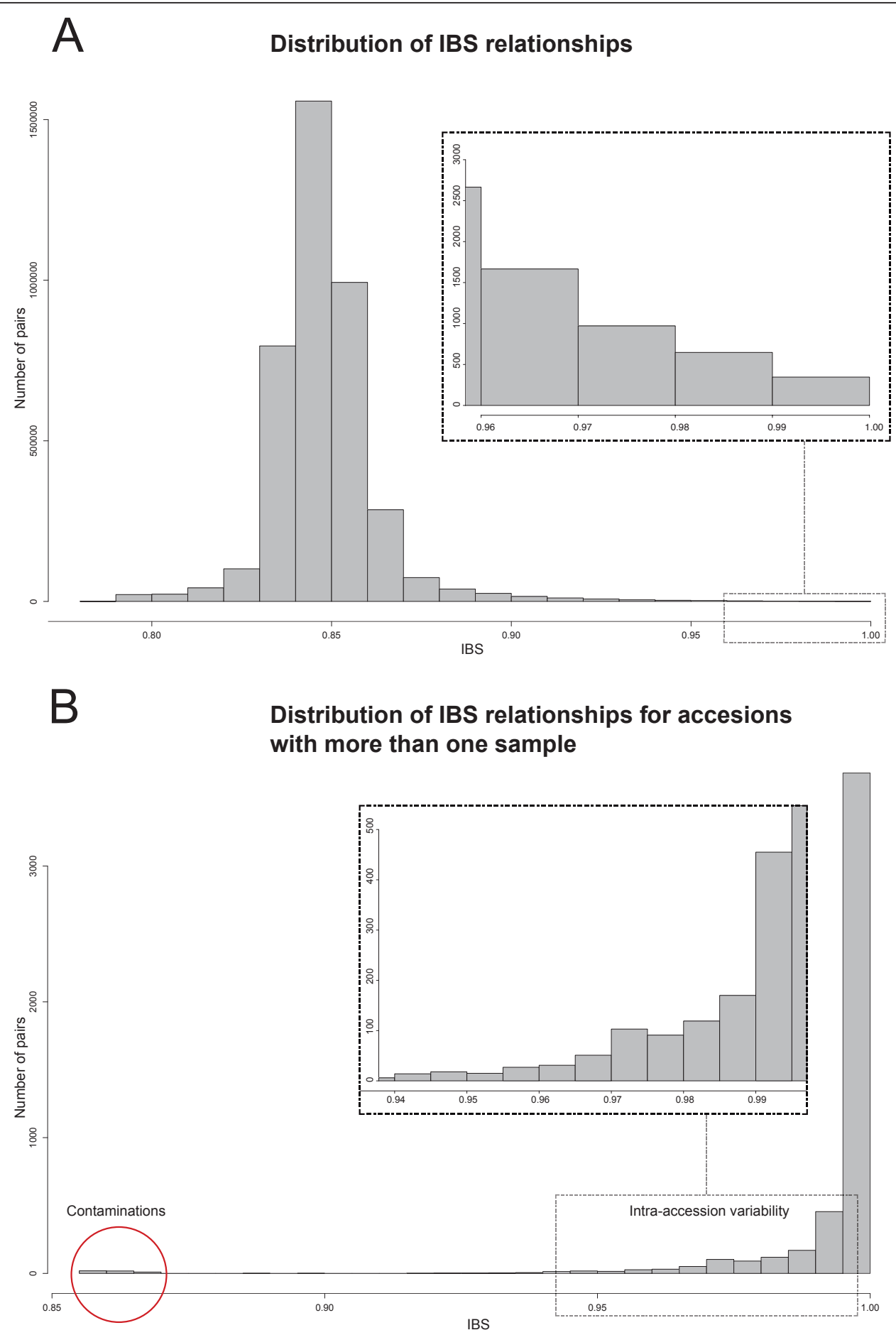

Figure 2 Identical by state (IBS) distribution across GBS samples. Distribution of IBS values across (A) the 2,815 accessions and (B) for accessions with multiple samples.

inbreds, and found that 603 lines (21\% of the collection) had at least one other accession that was $97 \%$ identical (equal to the relationship expected between a parental inbred and a progeny derived by four backcrosses to that parent). For some of the more historically important inbred lines, the number of relationships exceeded 10 . For example, B73 shares more than $97 \%$ of its genome with more than 50 inbreds (Figure 3), congruent with its contribution to the pedigrees of many important commercial lines [21]. 


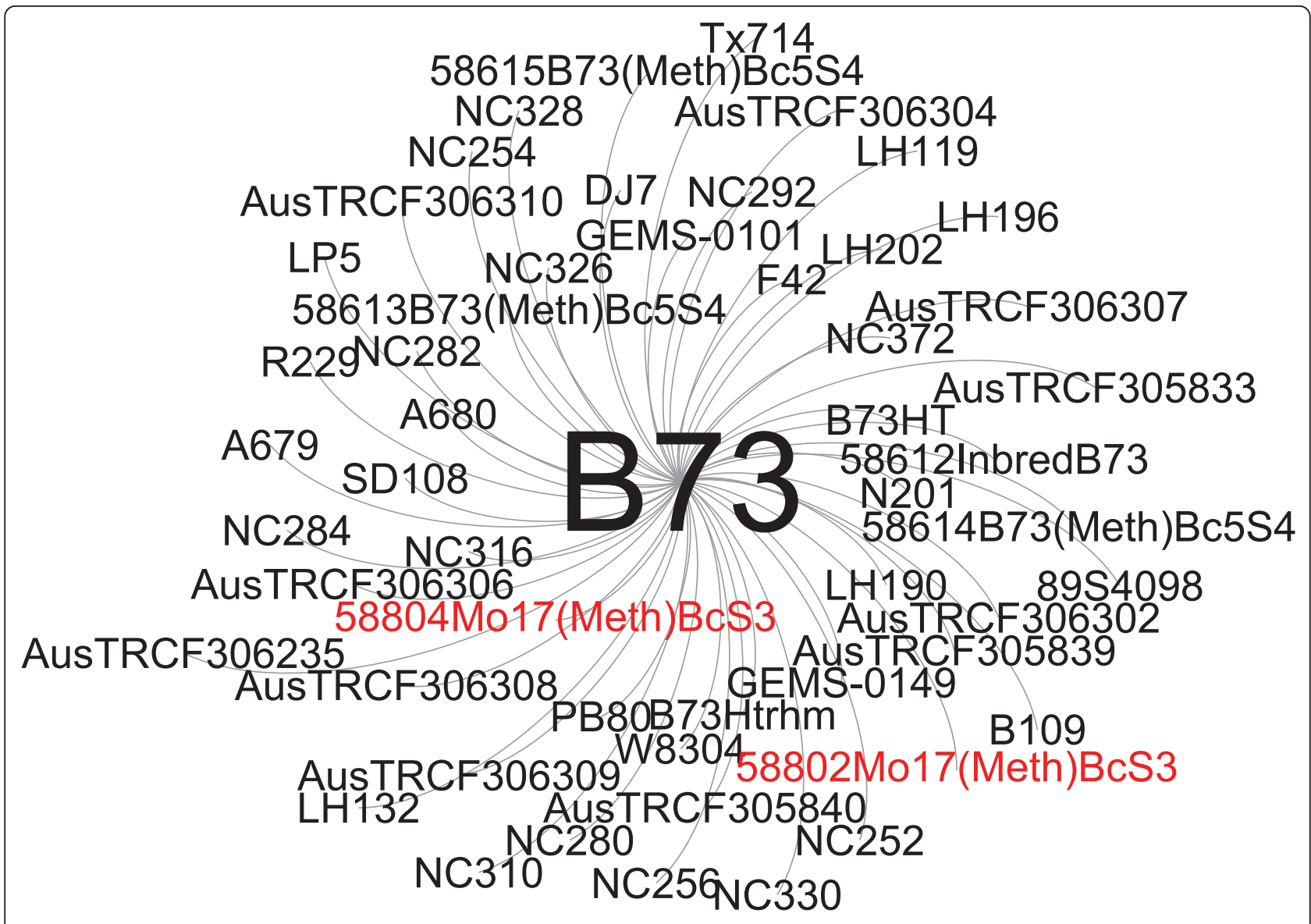

Figure 3 B73 network diagram. Network relationships of maize inbred lines with values of IBS greater than 0.97 for $B 73$.

The network of relationships obtained using GBS data (see Additional file 3), combined with pedigree information, provides a tool to identify anomalies and potential errors in the identity of accessions. These data, in hands of experts on maize germplasm (for example, the USDA maize curator), can be used to identify accessions that may have been misclassified, select best sources for multiplication/distribution, eliminate duplications, select core collections, add or recommend new experimental entries, and in theory, to assess genetic profile changes over successive regenerations, another quality-assurance measure.

\section{Population structure}

Maize lines from breeding programs with different objectives and environments were included in our final set of lines (see Additional file 1). It is expected that different groups of germplasm will result in population stratification $[7,8]$. An analysis of the similarity matrix using principal coordinate analysis (PCoA) with a multidimensional scaling (MDS) plot showed that GBS data could describe the genetic variation among our breeding lines in accordance with their known ancestral history (Figure 4A). For example, the inbreds grouped into different subpopulations along the PCo1 axis, with tropical materials on one side, and sweet corn, derived from Northern Flint materials, on the other.

When the inbreds were classified according to breeding program of origin (Figure 4B), the different breeding programs also tended to group together, with most of the USA programs in the two major germplasm groups recognized by temperate maize breeders (referred to as stiff stalk and non-stiff stalk [21]). However, some USA inbred lines (for example, the temperate-adapted all-tropical lines developed at North Carolina State University) were found to be interspersed with tropical lines from CIMMYT (the International Maize and Wheat Improvement Center), while others (for example, the semi-exotic inbreds from the Germplasm Enhancement of Maize (GEM) program, derived from crossing USA and tropical lines) were located between the stiff stalk/non-stiff stalk and the tropical clusters. Finally, other materials from international programs (for example, Spain, France, China, Argentina, or Australia) seem to represent germplasm pools different from those commonly used in North American programs. As expected, these usually did not form clusters with any of the other groups. 


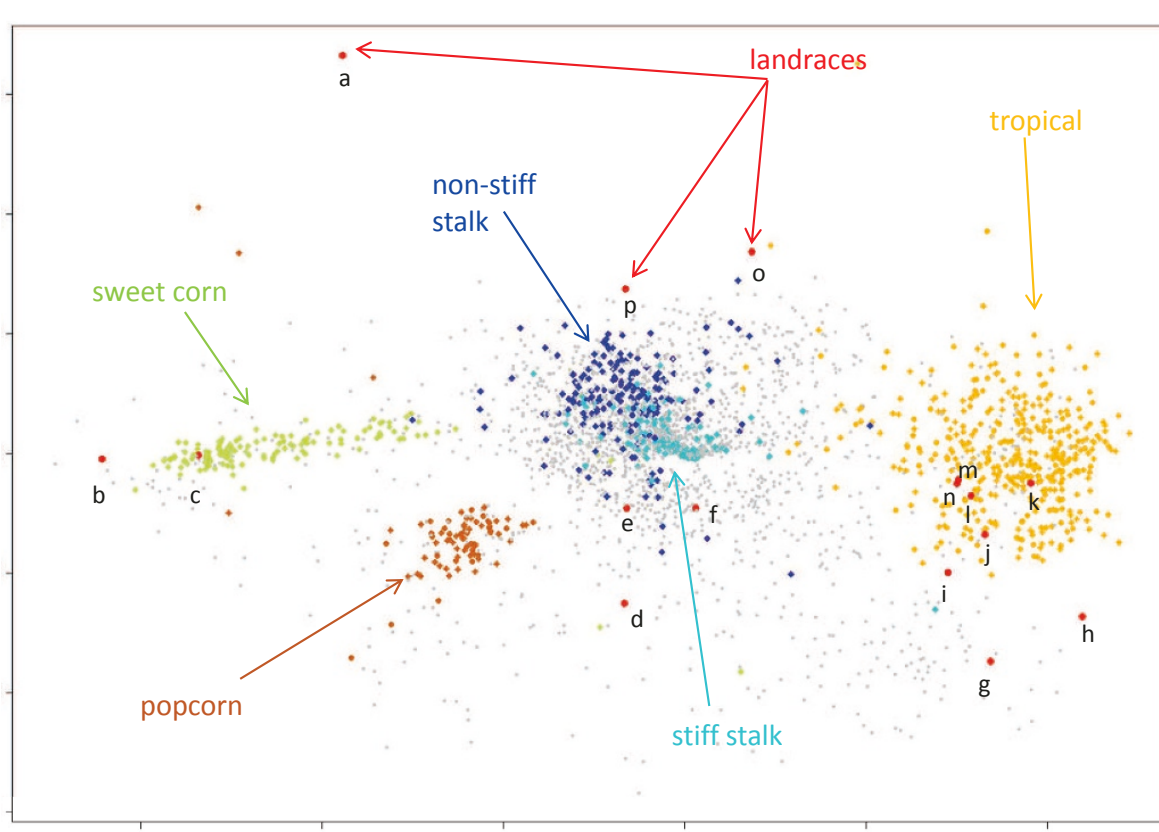

\section{LANDRACES}

a. Santo Domingo

b. Assiniboine

c. Longfellow flint

d. Pororo

e. Shoe Peg

f. Hickory King

g. Zapalote chico

h. Araguito

i. Cateto

j. Cravo

Riogranense

k. Tuxpeno

I. Costeno

m. Pollo

n. Cuban flint

o. Chapalote

p. Palomero de Jalisco

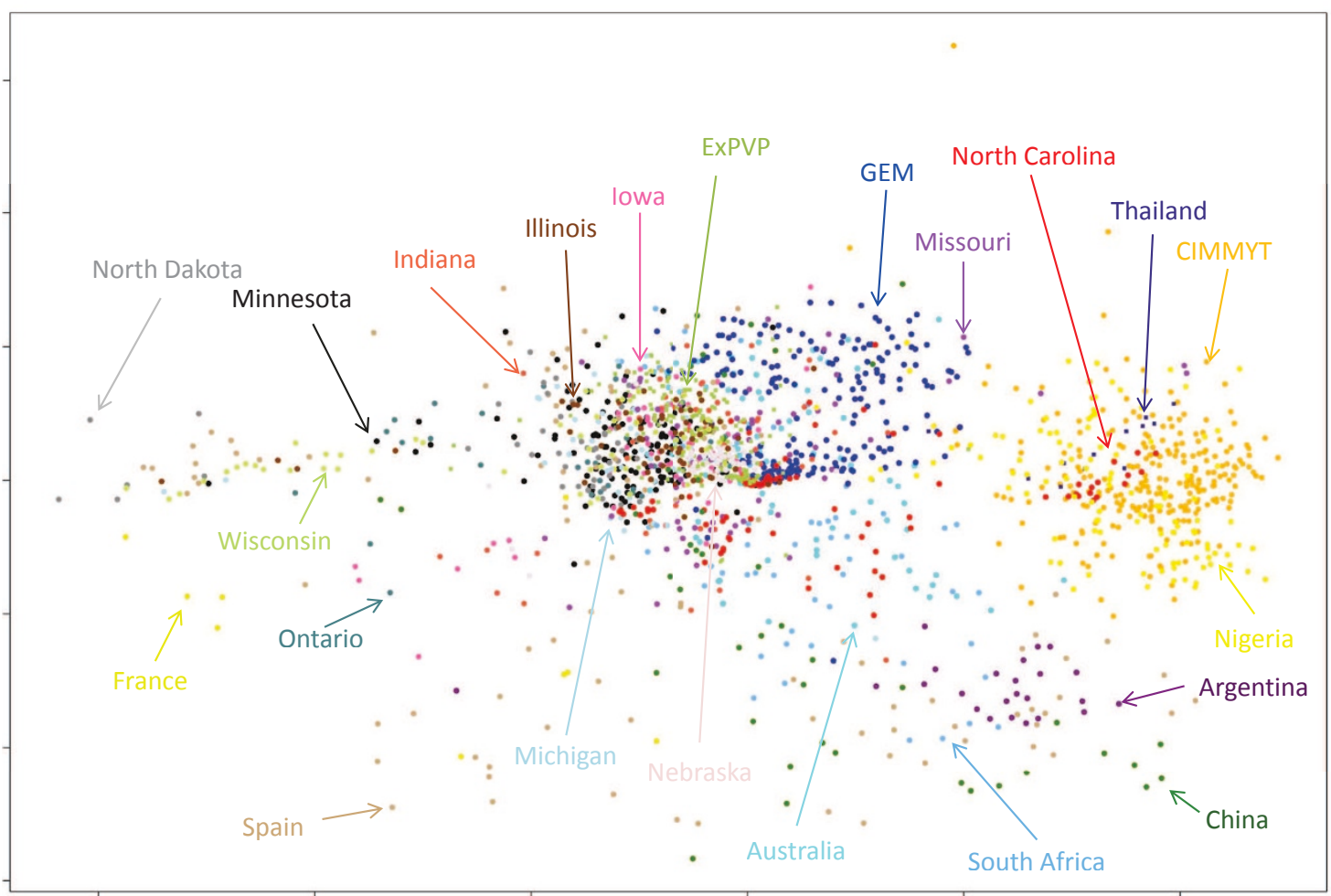

Figure 4 Multidimensional scanning for $\mathbf{2 , 8 1 5}$ maize inbred lines. Genetic relationships between the maize inbred lines preserved at the NCRPIS germplasm bank visualized using a principal coordinate analysis of the distances matrix. The $\times$ and $Y$ axes represent PCo1 and PCo2 respectively. Colors are assigned based on (A) population structure or (B) breeding program. Inbred lines obtained directly from landraces without selection are highlighted in red to serve as reference. 


\section{Distribution of alleles and allele frequencies}

The site frequency spectrum (SFS) for the entire collection showed that most of the SNPs in the Ames inbred panel $(68 \%)$ had a minor allele frequencies (MAF) less than 0.1, with more than half of all SNPs being rare $(\mathrm{MAF}<0.05)$ (Figure 5). This result suggests that some alleles might be unique to different subgroups of germplasm. To compare levels of diversity between different germplasm groups, we analyzed the percentage of alleles present in those groups. The inbreds of tropical origin were found to contain $77 \%$ of the total allelic diversity of the collection, whereas the non-stiff stalk and stiff stalk groups were found to present a substantial bottleneck, with only $48 \%$ and $42 \%$ of the total allelic diversity, respectively, being present. Of the total number of polymorphic SNPs, only about 35\% were shared between all three of the groups (Figure 5). Another difference between stiff stalk/non-stiff stalk and the remainder of the collection was a shift in the MAF distribution, with more than half of their SNPs $(68 \%$ and $59 \%$, respectively) having a MAF greater than 0.1. By contrast, the Goodman association panel captured $75 \%$ of the total allelic diversity and was highly representative of the entire collection, with an SFS similar to that obtained using all the samples. The diverse panel formed by the 27 maize inbred founders of NAM and IBM contained $57 \%$ of the overall allelic diversity, showing that, even with a very small number of samples, NAM captured more than half the total allelic diversity present in the inbred line collection.
Both Canadian and USA public breeding efforts have successfully incorporated genetic diversity. Collectively, those inbred lines contained $83 \%$ of the total allelic diversity of the collection. However, only a modest amount of this diversity has been commercially exploited, and proprietary germplasm with Expired Plant Variety Protection (ExPVP) contains only $45 \%$ of the total number of polymorphic SNPs. Moreover, private breeding efforts have favored the divergence between three main heterotic pools (stiff stalk, non-stiff stalk, and iodent). In analyzing the network relationships for the ExPVP inbreds, only $2 \%$ of the pairwise IBS relationships with greater than $90 \%$ IBS were found to be between inbreds from different heterotic pools (Figure $6 \mathrm{~A}$ ), and only $30 \%$ of the total SNPs segregating in the ExPVP materials were shared between all three groups of germplasm (Figure 6B).

We also analyzed pairwise fixation indexes (Fst) between different groups of accessions. The small Fst estimates, averaging only 0.06 , indicated that there is moderate differentiation [22] between tropical, stiff stalk, and non-stiff stalk maize populations. Analysis of pairwise Fst and average nucleotide divergence between different USA breeding programs (Table 1) confirmed the picture obtained by analyzing genetic distances. Most of those programs used similar sources of diversity, with an average pairwise Fst of 0.04 . Although the maximum values for nucleotide divergence between programs differed, the average values for all the comparisons were around 0.14 (Table 1). The main commercial

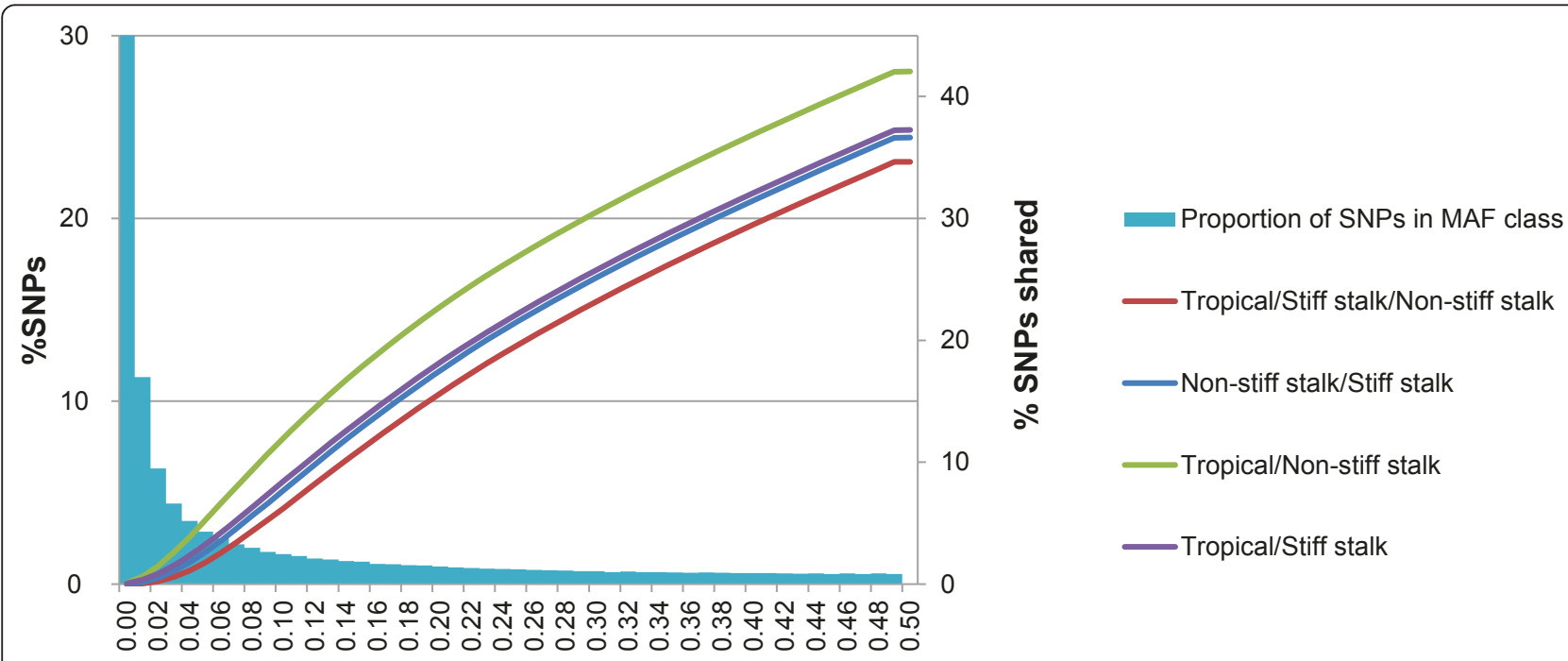

Minor Allele Frequency

Figure 5 Minor allele frequency (MAF) distribution and percentage of single-nucleotide polymorphisms (SNPs) shared between maize subpopulations. Histogram of MAF distribution over all groups, and cumulative percentage of SNPs shared between different groups of germplasm for each class of MAF. Columns represent the percentage of SNPs in each MAF category; lines represent the percentage of alleles shared between the groups of germplasm at equal or lesser MAF value. 
B

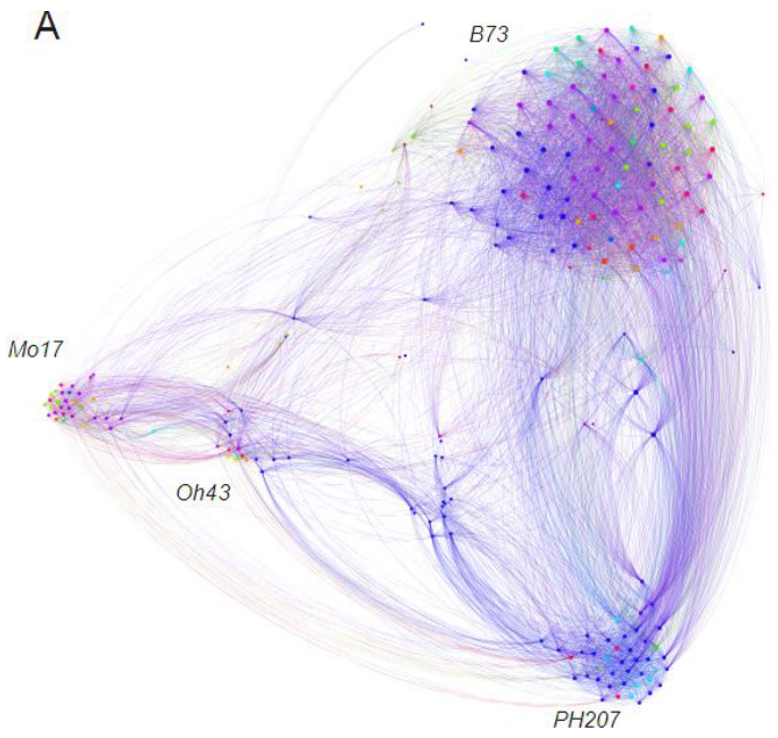

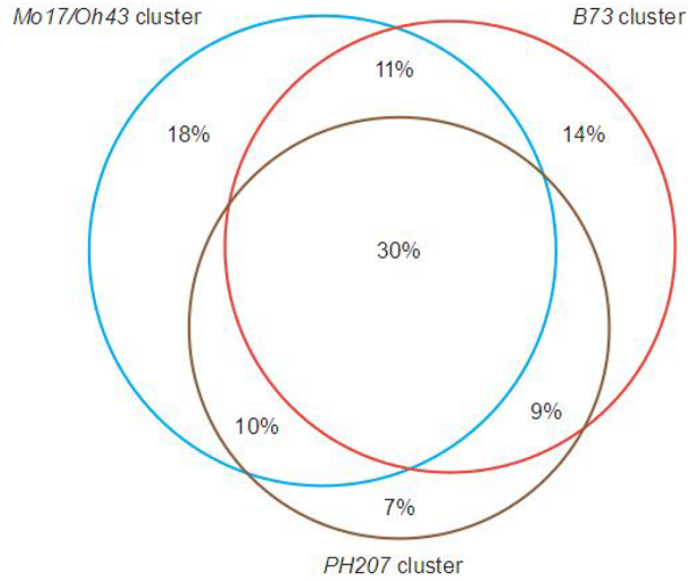

Figure 6 Expired Plant Variety Protection (ExPVP) network diagram and distribution of segregating single-nucleotide polymorphism (SNPs). (A) Network of relationships for the ExPVP inbreds constructed using identical by state (IBS) values greater than 0.9. Each dot (inbred line) has a different color assigned based on the company where it was developed. (B) Distribution of the segregating SNPs between the three heterotic groups that form the three main clusters in the network graph.

companies, responsible for most of the maize cultivated in the USA, have had very similar strategies when deciding which sources of germplasm will benefit their breeding programs and, based on the data obtained from their ExPVP, their populations differ genetically by only $3 \%$. They also had the smallest value for average nucleotide divergence (0.13).

Within chromosomes, all groups consistently displayed smaller values of Fst and lower MAF in the pericentromeric regions versus the remainder of the genome.

\section{Genetic diversity}

To evaluate the levels of diversity and divergence in the entire collection and within different groups of germplasm, we calculated LD, haplotype length, and population differentiation (Fst) across the entire maize genome. We also calculated the correlation between those measurements and previous recombination rates across the genome estimated with NAM [23] (Figure 7).

LD decayed very rapidly within the entire collection, and reached an average $r^{2}$ of 0.2 within about $1 \mathrm{~Kb}$ (Figure 8), but the variance is large because the level of LD is dependent on the particular group of germplasm and region of the genome, as can be seen with the differences for the median value for $r^{2}$ within diverse groups of germplasm (see Additional file 4). LD decay was slower within the stiff stalk, non-stiff stalk, and ExPVP groups, for which an average $r^{2}$ of 0.2 was not

Table 1 Pairwise differences between maize breeding programs in the USA. ${ }^{\text {a }}$

\begin{tabular}{|c|c|c|c|c|c|c|c|c|c|c|c|c|}
\hline & IL & IN & IA & MI & $\mathrm{MN}$ & MO & $\mathrm{NE}$ & NC & ND & w & Mon & Pion \\
\hline Illinois (IL) & & 0.140 .96 & 0.140 .99 & 0.140 .98 & 0.140 .97 & 0.150 .98 & 0.140 .98 & 0.140 .98 & 0.150 .93 & 0.150 .98 & 0.140 .98 & 0.140 .95 \\
\hline Indiana (IN) & 0.01 & & 0.140 .99 & 0.140 .95 & 0.140 .98 & 0.150 .99 & 0.140 .96 & 0.140 .96 & 0.150 .92 & 0.150 .96 & 0.140 .96 & 0.140 .96 \\
\hline lowa (IA) & 0.01 & 0.01 & & 0.140 .93 & 0.140 .99 & 0.150 .99 & 0.130 .99 & 0.141 .00 & 0.150 .99 & 0.140 .98 & 0.130 .99 & 0.140 .96 \\
\hline Michigan (MI) & 0.01 & 0.02 & 0.03 & & 0.140 .97 & 0.150 .93 & 0.140 .91 & 0.150 .91 & 0.150 .93 & 0.150 .97 & 0.140 .95 & 0.140 .92 \\
\hline Minnesota (MN) & 0.02 & 0.02 & 0.02 & 0.02 & & 0.150 .96 & 0.140 .98 & 0.150 .99 & 0.150 .94 & 0.140 .99 & 0.140 .98 & 0.140 .95 \\
\hline Missouri (MO) & 0.02 & 0.02 & 0.03 & 0.03 & 0.03 & & 0.140 .97 & 0.150 .95 & 0.150 .92 & 0.150 .99 & 0.140 .99 & 0.140 .96 \\
\hline Nebraska (NE) & 0.04 & 0.04 & 0.03 & 0.06 & 0.05 & 0.05 & & 0.140 .99 & 0.150 .89 & 0.140 .97 & 0.130 .98 & 0.130 .95 \\
\hline North Carolina (NC) & 0.05 & 0.05 & 0.04 & 0.06 & 0.05 & 0.04 & 0.06 & & 0.150 .90 & 0.150 .93 & 0.140 .98 & 0.140 .95 \\
\hline North Dakota (ND) & 0.03 & 0.03 & 0.04 & 0.03 & 0.02 & 0.03 & 0.08 & 0.06 & & 0.150 .94 & 0.150 .94 & 0.150 .88 \\
\hline Wisconsin (WI) & 0.02 & 0.03 & 0.03 & 0.03 & 0.02 & 0.04 & 0.07 & 0.07 & 0.03 & & 0.140 .98 & 0.150 .94 \\
\hline Monsanto (Mon) & 0.04 & 0.03 & 0.02 & 0.05 & 0.03 & 0.05 & 0.05 & 0.04 & 0.07 & 0.06 & & 0.130 .99 \\
\hline Pioneer (Pion) & 0.04 & 0.04 & 0.03 & 0.05 & 0.04 & 0.04 & 0.06 & 0.06 & 0.07 & 0.06 & 0.03 & \\
\hline
\end{tabular}

aLower diagonal shows pairwise Fst estimates between USA breeding programs, whereas upper diagonal shows average nucleotide divergence and maximum nucleotide similarity. 


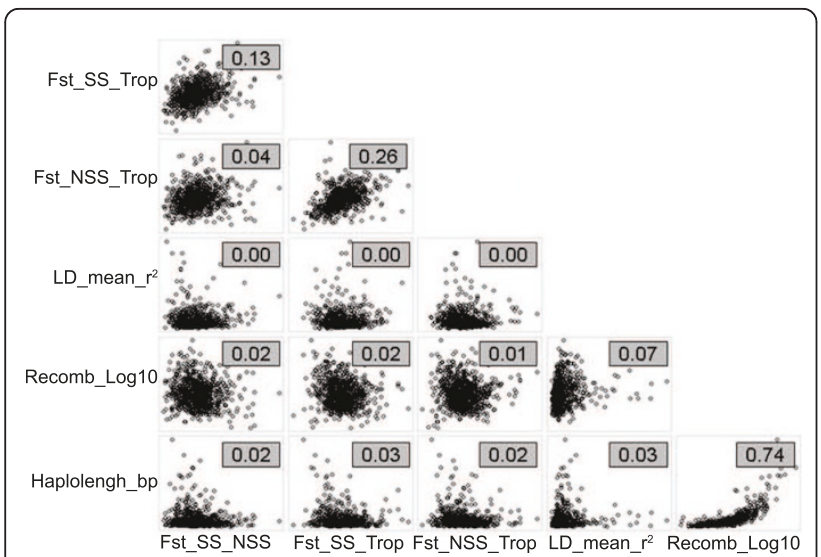

Figure 7 Genome-wide pairwise relationships between different genetic diversity measurements. Relationships between nested association mapping (NAM) recombination rate $\left(\log _{10} \mathrm{cM} / \mathrm{Mb}\right)$ average haplotype length (bp), average $L D\left(r^{2}\right)$, and fixation indexes (Fst) between stiff stalk, non-stiff stalk, and tropical lines at the NAM genetic map bin scale. The numbers indicate the coefficient of determination $\left(r^{2}\right)$ calculated using Spearman's rank correlation. LD, linkage disequilibrium.

reached until a distance of approximately $10 \mathrm{~Kb}$. Tropical materials displayed the fastest decay of LD with values similar to the overall sample.

The average GBS marker haplotype length, estimated around each SNP as the number of contiguous SNPs that two random lines from a group share, extending from a focal point forward in both directions, was 52 SNPs (around 1.4 Mb) for the entire collection, with a smaller length within the tropical materials (44 SNPs) and a much larger length in the non-stiff stalk (152 SNPs) and stiff stalk (495 SNPs) groups. The ExPVP group also displayed a large average haplotype length of 200 SNPs (around 5.1 Mb), with mean haplotype lengths greater for lines developed by breeding programs now owned by Monsanto than for Pioneer lines. Core collections such as the Goodman association panel or NAM parents, which were selected to maximize diversity, had the smallest haplotype lengths (81 and 48 SNPs, respectively) (Table 2). Haplotype lengths for the overall sample showed high correlation with the estimates of the recombination rates in NAM (Spearman correlation $r^{2}=0.74$ ) (see Additional file 5, Figure 7).

None of the other correlations tested was strong, probably because of the large diversity of the sample and large physical size of the NAM genetic map bins (average of 2.4 Mb). However, the fixation indexes between both temperate groups and tropical materials showed an $r^{2}$ of 0.26 , indicating common allele frequency differences between groups, probably related to the adaptation bottleneck.

In addition, when analyzing the entire chromosome with all samples, chromosome 4 was found to have a larger haplotype length (sites) compared with the rest of the chromosomes (Table 2). When looking at physical distance (in $\mathrm{Mb}$ ), this increase was consistent in all groups. One region on chromosome 4 that seemed to increase the average haplotype length is located between 40 and $65 \mathrm{Mb}$, a region with important genes related to the domestication and improvement processes $[24,25]$. This region also showed lower diversity and MAF. The stiff stalk, non-stiff stalk, and ExPVP groups also exhibit a longer than average haplotype length for chromosome 10 , where one of the major photoperiod response genes is located [26].

\section{Genome-wide association studies}

The germplasm set conserved in the USDA collection is extensive and publicly available, and contains a high amount of allelic diversity and rapid LD decay. For these reasons, we wanted to explore its possible use as a panel to study quantitative traits, combined with a strategy of low-coverage data in multiple samples. We used a simple Mendelian trait, namely, kernel color, with an

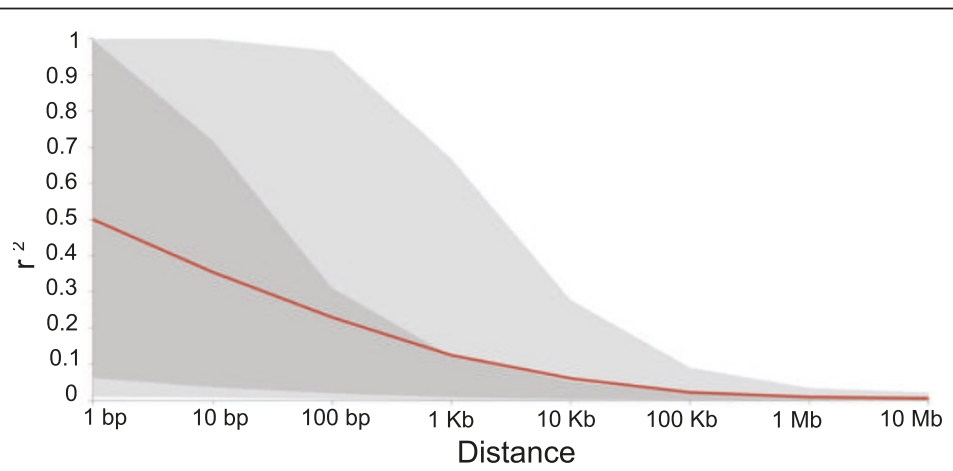

Figure 8 Decline of genome-wide linkage disequilibrium (LD) across all maize inbreds. Mean LD decay measured as pairwise $r^{2}$ between all single-nucleotide polymorphisms in the collection. The red line represents the average value while the darker gray area represents the $50 \%$ range of values and light gray $90 \%$. 
Table 2 Average haplotype length for different groups of germplasm. ${ }^{a}$

\begin{tabular}{|c|c|c|c|c|c|c|c|c|c|c|c|}
\hline \multirow[t]{2}{*}{ Type } & \multicolumn{10}{|c|}{ Chromosome number } & \multirow[t]{2}{*}{ Mean } \\
\hline & 1 & & 3 & 4 & 5 & 6 & 7 & 8 & 9 & 10 & \\
\hline All maize & 49.8 & 49.7 & 53.0 & 58.9 & 49.8 & 51.0 & 52.3 & 51.6 & 48.7 & 57.8 & 52.3 \\
\hline Tropical & 51.9 & 43.0 & 43.9 & 46.5 & 43.5 & 38.1 & 43.0 & 43.5 & 42.6 & 43.3 & 43.9 \\
\hline Stiff stalk & 494.4 & 493.3 & 546.6 & 523.5 & 432.9 & 527.8 & 410.5 & 488.9 & 388.4 & 647.0 & 495.3 \\
\hline Non-stiff stalk & 170.5 & 135.7 & 149.0 & 154.1 & 164.2 & 123.6 & 156.5 & 132.6 & 144.9 & 190.7 & 152.2 \\
\hline$\overline{E X P V P^{b}}$ & 200.8 & 203.0 & 170.8 & 216.1 & 192.5 & 186.0 & 179.4 & 209.3 & 168.8 & 277.4 & 200.4 \\
\hline Monsanto & 268.4 & 384.9 & 246.0 & 327.4 & 318.0 & 253.6 & 221.7 & 277.1 & 232.2 & 333.8 & 286.3 \\
\hline Pioneer & 223.6 & 139.6 & 167.8 & 226.5 & 170.5 & 198.9 & 206.7 & 175.6 & 188.3 & 267.2 & 196.5 \\
\hline Association panel & 79.6 & 79.8 & 90.1 & 87.4 & 76.3 & 81.7 & 75.3 & 81.9 & 76.2 & 86.4 & 81.5 \\
\hline NAM $^{c}$ & 45.0 & 45.4 & 53.6 & 57.0 & 47.9 & 43.3 & 43.3 & 52.3 & 43.4 & 52.1 & 48.3 \\
\hline
\end{tabular}

${ }^{a}$ Number of sites defining a haplotype by chromosome calculated using genotyping by sequencing; markers for different groups of germplasm.

b Expired Plant Variety Protection

c Nested association mapping

approximate frequency of $20 \%$ for white kernels in our population, to perform GWAS using GBS markers. The SNP with strongest association $\left(P=10^{-86}\right)$ with kernel color was found within the $Y 1$ gene that reduces the presence of carotenoid pigments in the endosperm [27] (see Additional file 6, Figure 9).

Because the power to detect alleles at lower frequencies is expected to be less, we decided to test another Mendelian trait, sweet corn versus starchy corn, where the sweet phenotype is present at a much lower frequency (5\%) than the white kernel type. This trait has been affected by strong selection pressure, both during domestication and the breeding process [28], resulting in an extensive block of elevated LD surrounding the targeted area, especially when the inbred is a dent line that has been converted into a sweet line. The two SNPs with strongest association $\left(P\right.$ values between $10^{-61}$ and $10^{-52}$ ) defined a $14 \mathrm{Mb}$ interval containing Su1, a gene that participates in kernel starch biosynthesis [29] (see Additional file 7, Figure 10).

Finally, we tested the power of this association panel with a complex trait, the number of growing degree days from planting to the day that $50 \%$ of the plants show silk (see Additional file 8, Figure 11). The best association, with $P=$ $10^{-23}$, lies about $2 \mathrm{~Kb}$ from $Z m C C T$, an important gene related to photoperiod response and flowering time in maize [26]. The second strongest associations ( $P$ values between $10^{-18}$ and $10^{-14}$ ) are located on chromosome 8 , surrounding the region where $\mathrm{Vgt1}$, one of the major flowering time QTL for maize is located [30]. The next best hit on chromosome $3\left(P=10^{-14}\right)$ does not have any identified candidate gene association, but overlaps with one of the flowering time QTL detected using NAM [31]. A chromosome 7 hit $\left(P=10^{-12}\right)$ also overlaps with one of the NAM

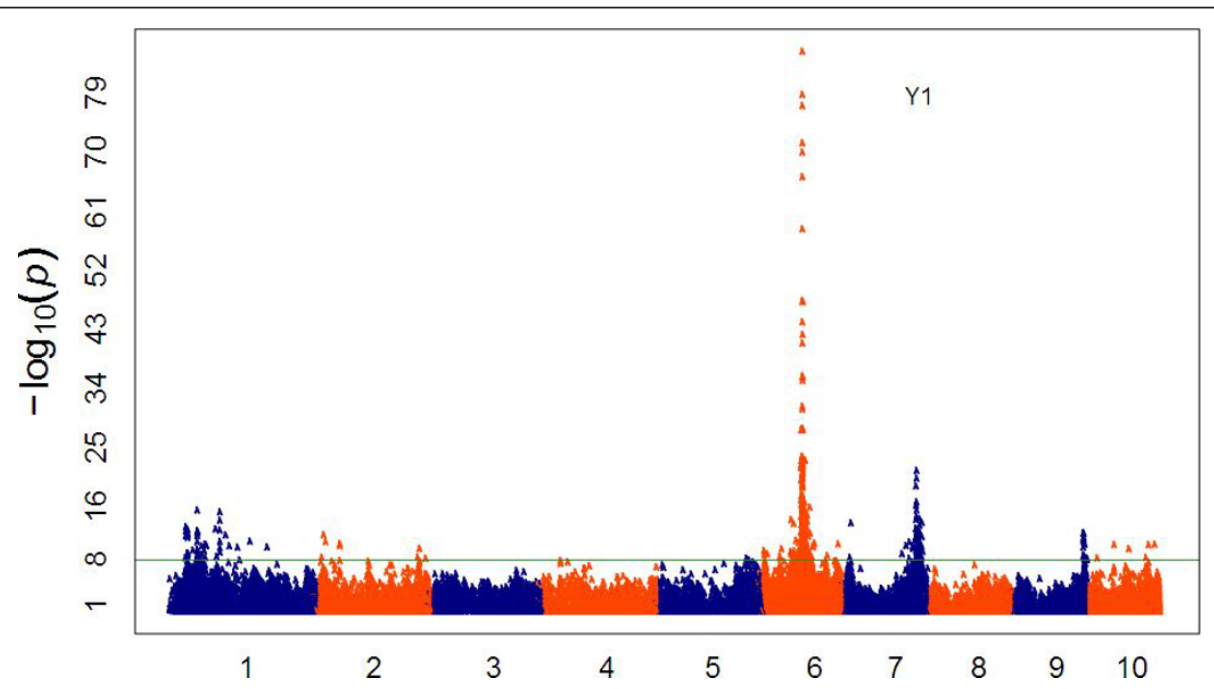

Figure 9 Genome-wide association study (GWAS) for yellow versus white kernels. GWAS for kernel color on 1,595 maize inbred lines with yellow or white kernels. 


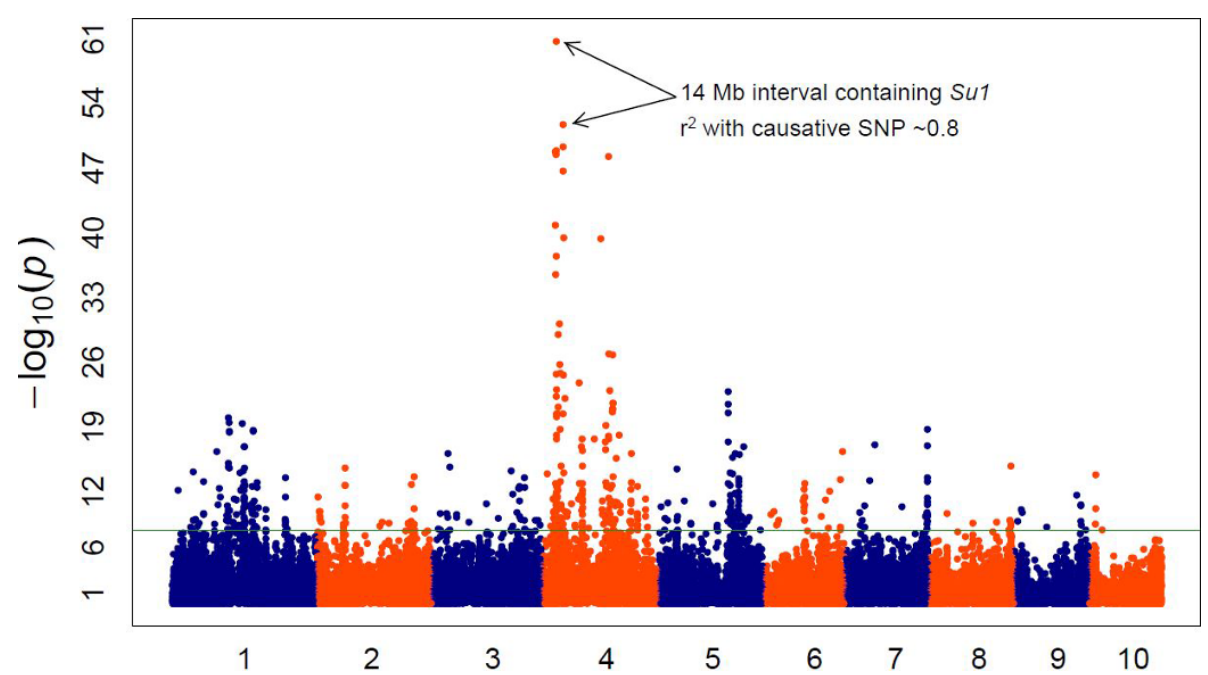

Figure 10 Genome-wide association study (GWAS) for sweet versus starchy corn. GWAS for kernel color on 2,145 maize inbred lines with sweet or starchy kernels. SNP, single-nucleotide polymorphism.

flowering time QTL [31] and is close to the maize flowering time gene DLF1-DelayedFlowering1 [32] and the GRMZM2G017016 gene, a putative orthologue of the Arabidopsis FRI-Frigida gene [33]. The fifth best hit, on chromosome 1, is located near a very interesting suite of genes spread across a $3 \mathrm{Mb}$ interval, where teosintebranched 1 and dwarf 8 flank one side, while PhytochromeA1 flanks the other side [34]. A gene, GRMZM2G1 44346, containing a CCT domain is also located in the region, only $0.2 \mathrm{Mb}$ away from our hit. Recent work has suggested that $d$ warf 8 has been a target of selection in early flowering lines $[35,36]$, but it is unlikely to directly contribute much to flowering time [37]. These regions certainly warrant further study.

\section{Discussion}

The challenges currently facing agriculture, that is, rapid human population growth, climate change, and the need to balance increasing production with reduced environmental effects, make it necessary to optimize the use of available resources. Genomic data can be used to address these challenges by helping breeders to compare individual plant genomes and optimize the characterization, discovery, and use of functional genetic variation [38]. Germplasm banks around the world curate thousands of maize accessions that, in combination with genomic data, can be explored through GWAS or GS, and could potentially be used for improving agriculturally significant quantitative traits. Inexpensive methods to obtain dense genetic

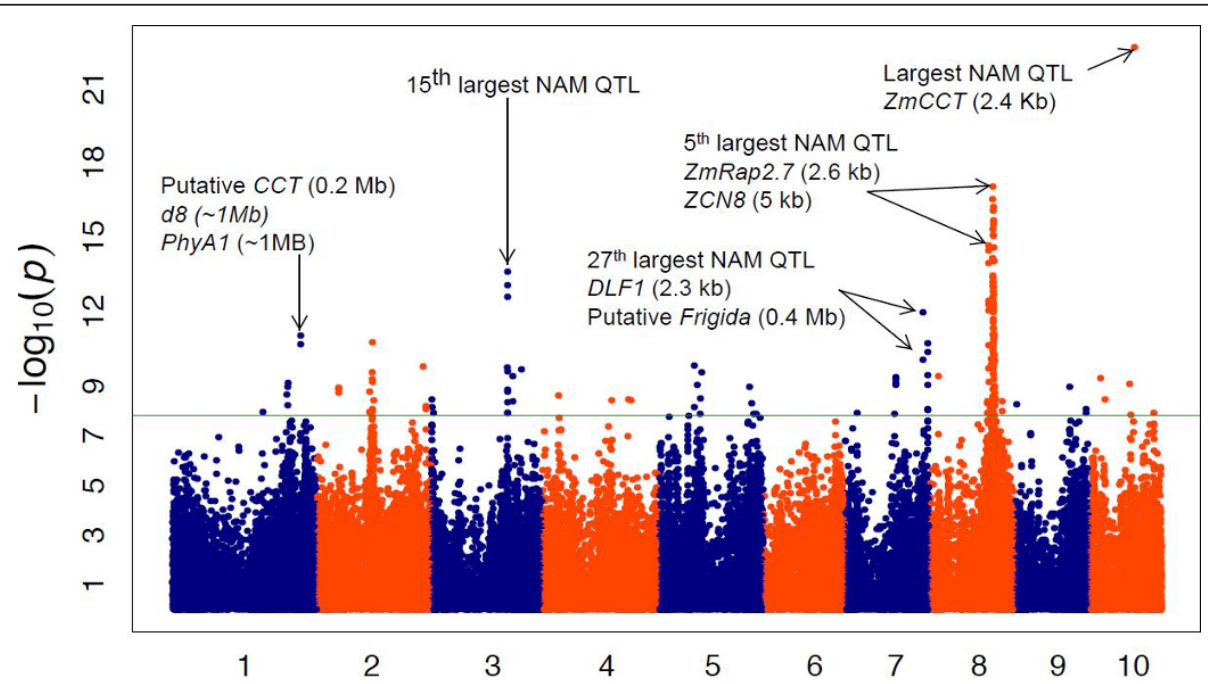

Figure 11 Genome-wide association study (GWAS) for growing degree days to silking. GWAS for growing degree days to $50 \%$ silking on 2,279 maize inbred lines. NAM, nested association mapping; QTL, quantitative trait loci. 
marker information on large samples of germplasm are needed to take full advantage of this tremendous resource [39].

The enormous progress in sequencing technologies that has occurred over the past few years has allowed better understanding of the maize genome. High-density genome sequencing has been used to study maize diversity [4,23-25]. In addition, several studies [39-42] have taken advantage of recently developed SNP genotyping arrays for maize, which have evolved quickly from only a few thousand SNPs to more than 50,000. Although high-density genome sequencing can provide a larger number of markers and a more accurate vision of the genome, its expense has restricted it to only a few hundred samples per study. SNP arrays are cheaper and can analyze larger samples of germplasm; however diversity studies can be confounded by the fact that SNPs are developed using reference sources of diversity, which may cause an important ascertainment bias (Ganal et al [19] describes an example with $B 73$ and Mo17 in the maizeSNP50 chip). GBS has been shown to be a less expensive method for genotyping large numbers of samples, and provides many more SNPs than do SNP arrays. Although the use of a reference genome for calling SNPs from GBS data might cause bias and underestimate the amount of diversity from the groups more distant from the reference, the diversity picture obtained when analyzing the distance matrix seems to be closer to the expectations from simple sequence repeats studies [8], whole-genome sequencing, and maize domestication data [23] than that obtained with SNP arrays.

The percentage of missing data from GBS with enzymes such as ApeKI and the levels of coverage obtained here may be a problem for some applications, especially GWAS and GS. Although better coverage can be achieved with more repetitions of the samples, this will increase cost, and quickly reaches a point where there is little reduction in missing data with increased investment in repeated sequencing runs. Given the importance of PAV in maize $[2,3,24,43]$ some of the missing data are very probably due to the absence of some regions of the $B 73$ genome in other inbred lines. As shown here, simple imputation procedures based on identifying the most similar haplotype can be used to supply some of those missing data, and this imputation may be sufficiently accurate provided that similar haplotypes are present in the sample of genotypes. This kind of procedure may work better as the total number of maize samples in the GBS database increases, but it may also cause over imputation of data that are actually biologically missing as a result of a PAV. Alternative methods for handling missing SNP data in GBS datasets include an approach that avoids using a reference genome, such as the one recently used for switchgrass [44], or one that genetically maps individual GBS sequence tags as dominant markers [13].

Another important difference between the results obtained with GBS and the results from SNP array methods seems to be the MAF distribution. Whereas array assays seem to oversample SNPs with intermediate frequencies [45] even when analyzing diverse maize collections $[9,41]$, more than half of GBS SNPs within our collection are rare (this is especially true within some of the more diverse germplasm groups). As sequencing technologies improve, the number of rare alleles detected is increasing. In humans, recent studies have found that the majority of variable genomic sites are rare, and exhibit little sharing between diverged populations [46]. The importance of rare alleles is not yet completely clear, and further studies to understand the magnitude of their role causing observable phenotypic variation are underway [38]. There are strong arguments both in favor and against the rare allele model, which hypothesizes that quantitative traits are largely controlled by rare alleles of large effect $[15,17]$.

GWAS studies have shown that variation in some traits is related to rare alleles, and that those rare variants could explain an additional fraction of the missing heritability [15]. However, identifying rare variants through GWAS is challenging, and requires large sample sizes [38]. With the present work, we present an extensive genetic characterization of the maize inbred lines preserved by one of the largest crop germplasm banks in the world, using a method that detects rare alleles with high confidence levels. Moreover, our data show that when there are not enough resources to extensively evaluate the entire collection, a smaller number of samples (such as the maize association panel or even the NAM parents), can, if chosen based on appropriate criteria to maximize haplotype diversity, capture a high portion of the rare alleles, allowing detection of rare allele effects that may be desirable to incorporate into breeding programs.

A complication of using the entire USDA-ARS maize inbred collection for breeding or GWAS is the close relationships between some of the lines. When the seed yield of a few inbreds derived from the Iowa Stiff Stalk Synthetic and their derivatives facilitated the transition to singlecross hybrids, these inbreds became the female parents of choice for many breeding programs [47]. For example $B 73$, the main founder of the stiff stalk group, is closely related to more than 50 other inbred lines from different programs in the collection. Several germplasm sources were used to generate the male pool (non-stiff stalk). However, the visualization of the genetic relationships through the MDS shows that even if the non-stiff stalk group forms a larger cluster (revealing a higher amount of 
diversity), an overlap between the stiff stalk and non-stiff stalk group still exists.

As shown by the MDS plot and Fst values, most of the germplasm from classic breeding programs of the Corn Belt region is closely related. The bottleneck is even narrower when ExPVPs are examined. Using a much smaller sample of SNP markers, Nelson et al. [48] reported that most of the ExPVPs released in the past three decades could be clustered into six primary groups represented by six prominent public inbred lines. More recently, Mikel [49] studied the pedigree records of several inbreds registered until 2008, and found that the genetic contribution of the inbred Mo17 decreased, whereas that of Oh43 increased. Our analysis shows that the ExPVP inbreds tend to cluster into three main groups, with $B 73$, Mo17/Oh43, and PH207 being the principal connectors within each cluster. Although all of the major private seed companies are represented within each group (consistent with the small value of divergence between companies), Pioneer germplasm is represented more in the iodent group (including PH207) and more of its germplasm falls outside the three main clusters (B73, PH207/ Oh43, and PH207). This result is in concordance with the observed smaller average haplotype length of Pioneer germplasm.

Although the recycling of elite lines as breeding parents has markedly reduced the amount of diversity used by maize breeders over the past few decades, breeders have also been aware of the importance of maintaining and introducing diversity into their programs [50]. The determination of breeders to search for new sources of promising, exotic germplasm is reflected in the Ames inbred collection. For instance, the GEM program aims to broaden the germplasm base of corn hybrids grown by farmers in the USA [51]. Combining the efforts of public and private cooperators, this project has introduced tropical alleles into elite USA germplasm. Our molecular characterization of these materials shows that the GEM program has been effective, as most of its inbreds lie somewhere between the ExPVPs and tropical materials on the MDS plot. According to our results, other public programs that have succeeded in incorporating tropical diversity into their materials are North Carolina State University and the University of Missouri. On the other side of the graph, adaptation to colder climates has been accomplished using different heterotic pools within the Northern USA and Canadian programs. Overall, although inbred lines from breeding programs from other parts of the globe might have different haplotype combinations (related to the use of different breeding pools), the USA and Canadian public inbred lines preserved at NCRPIS capture most of the total allelic diversity uncovered in this study.

GBS has yielded the greatest number of SNPs ever obtained from a large maize association panel to date.
As seen with our GWAS analysis, the data can provide accurate mapping of simple and complex traits for the most important genes. Van Inghelandt et al. [52] suggested that with an association panel of 1,537 elite maize inbred lines, 65,000 SNPs should be sufficient to detect associations with the genes with biggest effects. $\mathrm{Lu}$ et al. [41] used a panel containing tropical and temperate materials, and suggested that 230,000 to 460,000 markers would be needed. However when comparing the results for the two locations with the best flowering time associations in our study, we observed that the most important flowering time gene, $Z m C C T$, was targeted with only one SNP, meaning that it could easily have been missed. By contrast, the Vgt1 peak showed more than 80 SNPs associated with the trait (Figure 11). The main difference between these two important QTL is that the $Z m C C T$ polymorphism is very rare in temperate materials with very low levels of $L D$, whereas the $V g t 1$ variation is common in temperate inbred lines that have higher LD. When GBS data are used to perform GWAS, the probability of finding the causative SNPs in the dataset is highly dependent on the trait itself and the germplasm in which it is expressed. The length and number of the haplotypes detected vary enormously, depending on the region of the genome and the germplasm group. Some germplasm groups are currently under-represented in our maize dataset. As a result, population bottlenecks can cause a polymorphism that is not present at an appreciable frequency to pass the GBS pipeline quality filters. Therefore, it is unlikely that a causative polymorphism is present in the GBS dataset if it is unique to one of these germplasm groups. In addition, if the region has high haplotype diversity, rapid LD decay indicates that it is very likely that, even with approximately 700,000 SNPs we might not find a marker in LD with a particular causative polymorphism of interest. This situation is reflected in a large portion of chromosome 10 where the $Z m C C T$ gene is located, and tropical inbreds have much greater haplotype diversity than the rest of the collection. This means that, although 700,000 SNP markers are likely to be sufficient for analysis of temperate alleles, they are not sufficient to perform accurate GWAS with tropical alleles.

However, numerous inbreds in the collection are IBD for specific regions, allowing a strategy of accurate imputation. Based on common local haplotypes defined with GBS SNPs, high-density markers for a representative inbred obtained through whole-genome sequencing can be imputed between GBS markers, thereby increasing marker density.

In summary, our GWAS results for days to silking showed that this association panel combined with the GBS information can help to dissect the genetic architecture of important agronomic complex traits. Our best 
association signals corresponded to regions in which $a$ priori candidate genes or previously identified flowering time QTL are located. Nevertheless, identifying the causal gene is complex. Excluding the $Z m C C T$ gene hit on chromosome 10, all other major associations contain several SNPs. These hits cover regions that can extend for more than $10 \mathrm{Mb}$, even though our average LD decays very rapidly. For Arabidopsis [53] and rice [54], the results suggest that the occurrence of these 'mountain landscapes' could be related to the presence of several linked genes across the region. In maize, the dissection of a candidate region contributing to flowering time variation on chromosome 6 suggests that a cluster of tightly linked genes are responsible for the phenotypic variation [55]. In our study, the linked associations on chromosome 8 correspond with the position of two known flowering time genes, ZmRap2.7 [30] and ZCN8 [56]. A similar situation occurs for the hits on chromosome 7 with candidates DLF1 and FRI. Lastly, on our chromosome 1 region, extended haplotype lengths for some subpopulations and a strong correlation between the region and population structure have been reported [37]. Within $3 \mathrm{Mb}$, there are genes that have been under selection since the domestication of maize including $t b 1$ and $d 8$ [25,36] and two strong candidate genes for flowering time (CCT and PhyA1). All these results for our candidate regions support the hypothesis of the presence of some multigene complexes that may have evolved together during the process of maize domestication and adaptation. Further studies to unravel these regions and better understand the genetic architecture of flowering time are needed. Flowering time and adaptation to temperate climates are complex traits that seem to be controlled by several genes with small effects, organized in clusters across the genome.

\section{Conclusions}

As previous studies have suggested [7,8,39], the genetic diversity preserved at germplasm banks can be a useful resource for breeders and geneticists. Development of new germplasm will benefit from the knowledge of alleles from diverse materials associated with targeted traits [57], and from the methods and tools used to mine and translate this knowledge into products. However, collections may remain a hidden treasure if the amount and distribution of genetic diversity preserved is not understood, preventing users from making the right choices with the available material. With this study, we have provided the maize research community with a new tool that can be used to better understand and manipulate the genetic architecture of complex traits. It will permit more efficient and targeted use of the breeders' work and of the vast amount of diversity available in the USDA-ARS maize germplasm bank. Experimental designs based on particular haplotypes or maximizing the diversity for a determined number of entries may be possible, optimizing the resources available to each researcher.

\section{Materials and methods}

\section{Sample collection and genetic characterization}

Leaf samples from the entire available collection of maize inbred lines conserved at the USDA Plant Introductory extension in Ames (IA), including several sources for the same accession, and from other collaborators, were collected from an experiment planted near Columbia-Missouri (MO) in 2010. Several checks across the experimental design were planted in order to collect accurate phenotypic data. Leaf samples from those checks were also collected to serve as controls during the DNA manipulation process. DNA extractions were performed on leaf punches from a single plant using a commercial kit (DNeasy 96 Plant Kit, Qiagen Inc., Valencia, CA, USA). DNA from the Goodman association panel was provided by the Institute for Genomic Diversity (Cornell University, Ithaca, NY, USA) This panel was sequenced twice to serve as technical replicates for quality control. Another 95 additional samples from the entire collection were selected to maximize diversity, and sequenced several times with the same purpose and as sources of data for imputation.

Genotype data was generated following the GBS protocol [13], using ApeKI as restriction enzyme and multiplexing 96 samples on each Illumina flow cell lane. Raw reads from the machine for the samples reported here were analyzed in conjunction with approximately 18,000 additional maize samples, including NAM and other linkage populations. The GBS sequencing data has been submitted to NCBI SRA (study accession number SRP021921). The GBS discovery pipeline for species with a reference genome, available in TASSEL (version 3.0) [58], was used. The pipeline parameters used to filter the SNPs were a minimum SNP call rate of $10 \%$, minimum inbreeding coefficient (coefficient of panmixia, $1-\mathrm{H}_{\mathrm{O}} / \mathrm{H}_{\mathrm{E}}$, where $\mathrm{H}_{\mathrm{O}}=$ observed heterozygosity and $\mathrm{H}_{\mathrm{E}}$ $=$ expected heterozygosity) of 0.8 , and MAF of $0.2 \%$. For the 'biparental error correction' step that uses the information of biparental populations present in the overall sample, we used a maximum error rate (apparent MAF in biparental families where the SNP is not actually segregating) of 0.01 , and a minimum median $r^{2}$ for LD with markers in the local genome region across biparental families of 0.5. For the latter parameter, the $r^{2}$ for each individual biparental family in which a SNP was segregating (minimum MAF of 0.15) was calculated as the median $r^{2}$ in a window centered on the SNP in question and consisting of one-twentieth of the SNPs on the corresponding chromosome. SNPs within $100 \mathrm{~Kb}$ 
of the SNP in question were excluded from the calculation, as they could alter the result because of possible errors in the order of the sequenced bacterial artificial chromosomes.

The imputed data used for the GWAS was generated using a custom Java script that divided the entire SNP dataset into 1,024 SNP windows and looked for the most similar inbred line within each window to fill the missing data. The algorithm takes advantage of small IBD regions shared between pairs of inbred lines in the collection; if the window from the closest neighbor has more than 5\% difference from the line being imputed, the data point is left as missing. The entire GBS Zea database (approximately 22,000 samples) was used to search for the closest sample.

Both GBS SNP datasets (raw and imputed) are publicly available through Panzea [59]

\section{Population structure and pedigree relationships}

IBS and IBD were calculated for all possible pairwise comparisons using PLINK (version 1.07) [60]. For each individual, the values for the nearest neighbors, based on how similar (IBS) they were, were summarized using the '-cluster -neighbour' option in PLINK. To maintain the assumption of independence between markers for the IBD calculations, SNPs were pruned with a window of 100 adjacent SNPs and a step size of 25 SNPs. The $r^{2}$ threshold was 0.2 . The resulting number of remaining SNPs was approximately 200,000.

Network diagrams were generated using the opensource network visualization platform Gephi (version 0.8) [61].

MDS through principal coordinates analysis for two dimensions was performed on the IBS matrix using the isoMDS option of the package MASS from $R$ [62]. Accessions were assigned to a specific group or breeding program according to the information available in the Germplasm Resources Information Network (GRIN) database.

\section{Distribution of alleles and allele frequencies}

MAF were calculated using the 'Geno Summary by Site' analysis tool in TASSEL (version 4.0) [58]. Taxa and site filter tools from that program were also used. To remove possible sequencing errors, only alleles detected in at least two individuals in a particular group were considered to be present for the allelic diversity calculations.

\section{Genetic diversity}

To analyze genetic diversity, each inbred was considered a random sample of a single maize haplotype from the populations being examined. Hence, heterozygous SNP genotypes were set to 'missing'. With the resulting dataset, pairwise IBS for all pairs of individuals from each set of populations being compared was calculated for each $1 \mathrm{Mb}$ window. Average nucleotide difference was defined as 1 minus average IBS. To estimate average haplotype length, we followed the procedure proposed by Hufford et al.[25]. Choosing one random starting data point across the genome and two random inbred lines, we compared the genotypes of the two lines at the focal point, extending outward in both directions until we found different genotypes, then we sorted the results according to the median site to calculate the average distribution per interval. Filtering for allele frequency was not applied before this calculation. Consequently, in order to allow for possible sequencing errors, a oneSNP mismatch was permitted on each side of the initial counting site before assigning the end of the haplotype. Pairwise Fst between each group of maize lines were calculated for all the SNPs as described by Weir and Cockerham [63], and an average Fst by Mb window was presented. All genetic diversity calculations were performed using custom Java and R scripts.

For the LD analysis, SNPs with more than $25 \%$ missing data and with a MAF less than 0.05 were filtered before the analysis, resulting in a total set of 21,806 SNPs. To avoid the bias that differences in sample sizes of the different populations could cause, one random set of 180 inbreds from each of the tropical, ExPVP, and overall populations was selected. LD was calculated using TASSEL [58], and output report tables from that program were summarized using $R$.

\section{Genome-wide association analysis}

The GRIN database contains public information for different descriptors for each of its entries. When these analyses were performed, kernel color phenotypes were available for 1,595 accessions (1,281 yellow versus 314 white). We first performed a GWAS for kernel color, with white kernels coded as 0 and yellow as 1 . In addition, information about kernel type was used to analyze starchy corn (0) versus sweet corn (1), with 2,520 entries in the first category and 140 into the second. Data on flowering time were collected from plants grown in randomized augmented designs in three environments (Ames, IA; Clayton, NC; and Aurora, NY) during summer 2010. Growing degree days were calculated using climate data from weather stations located near the farms. Best linear unbiased predictors for each line across environments were constructed with ASREML software (version 3.0) [64]. Blocking factors included environment, field nested in environment, and block nested in field. Each field environment error was assumed to be independent and heterogeneous in variance. A first-order autoregressive error term for range and row error structures in each field were also included.

GWAS analyses were performed on the imputed dataset using the GAPIT package for R [65]. For the $10 \%$ 
unimputed (missing) genotypes, the GWAS model assigned an intermediate value before the analysis. For all traits, we used a compressed mixed model [66], where the kinship was calculated as described by VanRaden [67], with a random subset of $10 \%$ of the SNPs. The first five principal components calculated with those same SNPs were included as covariates.

\section{Additional material}

Additional file 1: Table S1. Details for the 2,815 accessions (accession number, number of samples, number of plants, average identical by state (IBS) value for all the samples, percentage of missing data, breeding program, and pedigree group).

Additional file 2: Table S2. The 10 closest neighbors for each unique entry in our maize list based on identical by state (IBS) values. IBS value for each neighbor is presented between brackets.

Additional file 3: Figure S1. Network diagram showing the relationships of maize inbred lines with identical by state (IBS) values greater than 0.96 .

Additional file 4: Figure S2. Median linkage disequilibrium (LD) decay measured as pairwise $r^{2}$ between all single-nucleotide polymorphisms (SNPs) in the collection. Each line represents a different group of germplasm.

Additional file 5: Figure S3. Relationships between nested association mapping (NAM) recombination rate $\left(\log _{10} \mathrm{CM} / \mathrm{Mb}\right)$, average haplotype length (bp), average linkage disequilibrium (LD) $\left(r^{2}\right)$, and fixation index (Fst) between stiff stalk, non-stiff stalk, and tropical lines at the NAM genetic map bin scale for each chromosome. The numbers indicate the coefficient of determination $\left(r^{2}\right)$ calculated using Spearman's rank correlation.

Additional file 6: Figure S4 Quantile-quantile (QQ) plot for kernel color genome-wide association study (GWAS) analysis.

Additional file 7: Figure S5 Quantile-quantile (QQ) plot for sweet corn genome-wide association study (GWAS) analysis.

Additional file 8: Figure S6 Quantile-quantile (QQ) plot for floweringtime genome-wide association study (GWAS) analysis.

\section{List of abbreviations}

BWA: Burrows-Wheeler Alignment; ExPVP: Expired Plant Variety Protection; Fst: Fixation index; GBS: Genotyping by sequencing; GEM: Germplasm Enhancement of Maize; GRIN: Germplasm Resources Information Network; GS: Genomic selection; GWAS: Genome-wide association study; IBD: Identity by descent; IBS: Identical by state; LD: Linkage disequilibrium; MAF: Minor allele frequencies; MDS: Multidimensional scaling; NAM: Nested association mapping; NCRPIS: North Central Regional Plant Introduction Station; PAV: Presence/absence variation; PCoA: Principal coordinate analysis; QQ: Quantile-quantile; SFS: Site frequency spectrum; SNP: Single-nucleotide polymorphism; USDA-ARS: USA Department of Agriculture - Agricultural Research Service

\section{Authors' contributions}

MCR analyzed the data and drafted the manuscript. MJM curates the germplasm collection: participated in the design and coordination of the study, and provided phenotypic information. JCG contributed with new analysis tools and analyzed data. JAP analyzed data. KLS and TMC contributed with new analysis tools. RJE, CBA, and SEM coordinated and performed the GBS lab protocol. SAF-G and MDM conceived of the study, participated in the study design and coordination, and collected data. JBH conceived of the study, participated in the project design and coordination, collected data, and helped to draft the manuscript. ESB and CAG conceived of the study, managed its design and coordination, collected data, and helped to draft the manuscript. All authors read and approved the final manuscript.

\section{Competing interests}

The authors declare that they have no competing interests.

\section{Acknowledgements}

We thank Dr Alvarez, Dr Edwards, Dr Goodman, Dr Krakowksy, Dr Ordás, and Dr Warburton, for providing seed for the new entries, all the people who collaborated with field management and collection of phenotypic data, and Dr Bradbury and Sara J Miller for their review and edits of the manuscript.

\section{Author details}

${ }^{1}$ Institute for Genomic Diversity, Biotechnology bldg., Cornell University, Ithaca, NY, 14853, USA. ${ }^{2}$ USA Department of Agriculture (USDA) - Agricultural Research Service (USDA-ARS. ${ }^{3}$ North Central Regional Plant Introduction Station, Agronomy bldg., Department of Agronomy, lowa State University, Ames, IA, 50001, USA. ${ }^{4}$ Bioinformatics Research Center, Thomas Hall, North Carolina State University, Raleigh, NC, 27606, USA. ${ }^{5}$ Department of Plant Breeding and Genetics, Bradfield Hall, Cornell University, Ithaca, NY, 14853, USA. 'Division of Plant Sciences, Curtis Hall, University of Missouri, Columbia, MO, 65211,USA. 'Department of Crop Science, Williams Hall, North Carolina State University, Raleigh, NC, 27695, USA.

Received: 26 February 2013 Revised: 30 April 2013

Accepted: 11 June 2013 Published: 11 June 2013

\section{References}

1. FAOSTAT.. [http://faostat.fao.org].

2. Fu H, Dooner HK: Intraspecific violation of genetic colinearity and its implications in maize. Proc Natl Acad Sci USA 2002, 99:9573-9578.

3. Morgante M, Brunner S, Pea G, Fengler K, Zuccolo A, Rafalski A: Gene duplication and exon shuffling by helitron-like transposons generate intraspecies diversity in maize. Nat Genet 2005, 37:997-1002.

4. Chia J-M, Song C, Bradbury PJ, Costich D, De Leon N, Doebley J, Elshire RJ, Gaut B, Geller L, Glaubitz JC, Gore M, Guill KE, Holland J, Hufford MB, Lai J, Li M, Liu X, Lu Y, McCombie R, Nelson R, Poland J, Prasanna BM, Pyhäjärvi T, Rong T, Sekhon RS, Sun Q, Tenaillon MI, Tian F, Wang J, Xu X, et al: Maize HapMap2 identifies extant variation from a genome in flux. Nat Genet 2012, 44:803-807.

5. Shull GH: The composition of a field of maize. American Breeders Association Report 1908, 4:296-301.

6. East EM: Inbreeding in corn. Rep Conn Agric Exp Stn 1908, 1:419-428.

7. Liu K, Goodman M, Muse S, Smith JS, Buckler ES, Doebley J: Genetic structure and diversity among maize inbred lines as inferred from DNA microsatellites. Genetics 2003, 165:2117-2128.

8. Flint-Garcia S, Thuillet A-C, Yu J, Pressoir G, Romero SM, Mitchell SE, Doebley J, Kresovich S, Goodman MM, Buckler ES: Maize association population: a high-resolution platform for quantitative trait locus dissection. Plant J 2005, 44:1054-1064.

9. Yang X, Gao S, Xu S, Zhang Z, Prasanna BM, Li L, Li J, Yan J: Characterization of a global germplasm collection and its potential utilization for analysis of complex quantitative traits in maize. Mol Breed 2010, 28:511-526.

10. Mezmouk S, Dubreuil P, Bosio M, Décousset $L$, Charcosset A, Praud S, Mangin B: Effect of population structure corrections on the results of association mapping tests in complex maize diversity panels. Theor App/ Genet 2011, 122:1149-1160

11. Yan J, Warburton M, Crouch J: Association mapping for enhancing maize (Zea mays L.) genetic improvement. Crop Sci 2011, 51:433-449.

12. Tian F, Bradbury PJ, Brown PJ, Hung H, Sun Q, Flint-Garcia S, Rocheford TR, McMullen MD, Holland JB, Buckler ES: Genome-wide association study of leaf architecture in the maize nested association mapping population. Nat Genet 2011, 43:159-162.

13. Elshire RJ, Glaubitz JC, Sun Q, Poland JA, Kawamoto K, Buckler ES, Mitchell SE: A robust, simple Genotyping-by-Sequencing (GBS) approach for high diversity species. PLoS One 2011, 6:e19379.

14. Schnable PS, Ware D, Fulton RS, Stein JC, Wei F, Pasternak S, Liang C, Zhang J, Fulton L, Graves TA, Minx P, Reily AD, Courtney L, Kruchowski SS, Tomlinson C, Strong C, Delehaunty K, Fronick C, Courtney B, Rock SM, Belter E, Du F, Kim K, Abbott RM, Cotton M, Levy A, Marchetto P, Ochoa K, 
Jackson SM, Gillam B, et al: The B73 maize genome: complexity, diversity, and dynamics. Science 2009, 326:1112-1115.

15. Park J-H, Gail MH, Weinberg CR, Carroll RJ, Chung CC, Wang Z, Chanock SJ, Fraumeni JF, Chatterjee N: Distribution of allele frequencies and effect sizes and their interrelationships for common genetic susceptibility variants. Proc Natl Acad Sci USA 2011, 108:18026-18031.

16. Yan J, Kandianis CB, Harjes CE, Bai L, Kim E-H, Yang X, Skinner DJ, Fu Z, Mitchell S, Li Q, Fernandez MGS, Zaharieva M, Babu R, Fu Y, Palacios N, Li J, Dellapenna D, Brutnell T, Buckler ES, Warburton ML, Rocheford T: Rare genetic variation at Zea mays crtRB1 increases beta-carotene in maize grain. Nat Genet 2010, 42:322-327.

17. Gibson G: Rare and common variants: twenty arguments. Nat Rev Genet 2012, 13:135-145.

18. McMullen MD, Kresovich S, Villeda HS, Bradbury P, Li H, Sun Q, FlintGarcia S, Thornsberry J, Acharya C, Bottoms C, Brown P, Browne C, Eller M, Guill K, Harjes C, Kroon D, Lepak N, Mitchell SE, Peterson B, Pressoir G, Romero S, Oropeza Rosas M, Salvo S, Yates H, Hanson M, Jones E, Smith S, Glaubitz JC, Goodman M, Ware D, et al: Genetic properties of the maize nested association mapping population. Science 2009, 325:737-740.

19. Ganal MW, Durstewitz G, Polley A, Bérard A, Buckler ES, Charcosset A, Clarke JD, Graner E-M, Hansen M, Joets J, Le Paslier M-C, McMullen MD, Montalent P, Rose M, Schön C-C, Sun Q, Walter H, Martin OC, Falque M: A large maize (Zea mays L.) SNP genotyping array: development and germplasm genotyping, and genetic mapping to compare with the B73 reference genome. PLoS One 2011, 6:e28334.

20. Carena MJ, Hallauer AR, Miranda Filho J: Quantitative Genetics in Maize Breeding. 3 edition. New York: Springer New York: 2010.

21. Mikel MA, Dudley JW: Evolution of North American Dent Corn from Public to Proprietary Germplasm. Crop Sci 2006, 46:1193-1205.

22. Wright S: Evolution and the Genetics of Populations: Genetics and Biometric Foundations v. 4 (Variability within and Among Natural Populations) Chicago: University of Chicago Press; 1978.

23. Gore MA, Chia J-M, Elshire RJ, Sun Q, Ersoz ES, Hurwitz BL, Peiffer JA, McMullen MD, Grills GS, Ross-lbarra J, Ware DH, Buckler ES: A firstgeneration haplotype map of maize. Science 2009, 326:1115-1117.

24. Lai J, Li R, Xu X, Jin W, Xu M, Zhao H, Xiang Z, Song W, Ying K, Zhang $M$, Jiao Y, Ni P, Zhang J, Li D, Guo X, Ye K, Jian M, Wang B, Zheng H, Liang H, Zhang X, Wang S, Chen S, Li J, Fu Y, Springer NM, Yang H, Wang J, Dai J, Schnable PS, et al: Genome-wide patterns of genetic variation among elite maize inbred lines. Nat Genet 2010, 42:1027-1030.

25. Hufford MB, Xu X, Van Heerwaarden J, Pyhäjärvi T, Chia J-M, Cartwright RA, Elshire RJ, Glaubitz JC, Guill KE, Kaeppler SM, Lai J, Morrell PL, Shannon LM, Song C, Springer NM, Swanson-Wagner RA, Tiffin P, Wang J, Zhang G, Doebley J, McMullen MD, Ware D, Buckler ES, Yang S, Ross-lbarra J: Comparative population genomics of maize domestication and improvement. Nat Genet 2012, 44:808-811.

26. Hung H-Y, Shannon LM, Tian F, Bradbury PJ, Chen C, Flint-Garcia SA, McMullen MD, Ware D, Buckler ES, Doebley JF, Holland JB: ZmCCT and the genetic basis of day-length adaptation underlying the postdomestication spread of maize. Proc Natl Acad Sci USA 2012, 109 E1913-E1921.

27. Buckner B, Kelson TL, Robertson DS: Cloning of the $y 1$ locus of maize, a gene involved in the biosynthesis of carotenoids. Plant Cell 1990, 2:867-876

28. Whitt SR, Wilson LM, Tenaillon Ml, Gaut BS, Buckler ES: Genetic diversity and selection in the maize starch pathway. Proc Natl Acad Sci USA 2002, 99:12959-12962

29. James MG, Robertson DS, Myers AM: Characterization of the maize gene sugary1, a determinant of starch composition in kernels. Plant Cell 1995, 7:417-429.

30. Salvi S, Sponza G, Morgante M, Tomes D, Niu X, Fengler KA, Meeley R, Ananiev E, Svitashev S, Bruggemann E, Li B, Hainey CF, Radovic S, Zaina G, Rafalski J, Tingey S V, Miao G, Phillips RL, Tuberosa R: Conserved noncoding genomic sequences associated with a flowering-time quantitative trait locus in maize. Proc Natl Acad Sci USA 2007, 104:11376-11381.

31. Buckler ES, Holland JB, Bradbury PJ, Acharya CB, Brown PJ, Browne C, Ersoz E, Flint-Garcia S, Garcia A, Glaubitz JC, Goodman MM, Harjes C, Guill K, Kroon DE, Larsson SJ, Lepak NK, Li H, Mitchell SE, Pressoir G, Peiffer JA, Oropeza Rosas M, Rocheford TR, Romay MC, Romero S, Salvo S, Sanchez Villeda H, Da Silva HS, Sun Q, Tian F, Upadyayula N, et al: The genetic architecture of maize flowering time. Science 2009, 325:714-718.
32. Muszynski MG, Dam T, Li B, Shirbroun DM, Hou Z, Bruggemann E, Archibald R, Ananiev E V, Danilevskaya ON: Delayed flowering1 encodes a basic leucine zipper protein that mediates floral inductive signals at the shoot apex in maize. Plant Physiol 2006, 142:1523-1536.

33. Johanson U, West J, Lister C, Michaels S, Amasino R, Dean C: Molecular analysis of FRIGIDA, a major determinant of natural variation in Arabidopsis flowering time. Science 2000, 290:344-347.

34. Sheehan MJ, Farmer PR, Brutnell TP: Structure and expression of maize phytochrome family homeologs. Genetics 2004, 167:1395-1405.

35. Thornsberry JM, Goodman MM, Doebley J, Kresovich S, Nielsen D, Buckler ES: Dwarf8 polymorphisms associate with variation in flowering time. Nat Genet 2001, 28:286-289.

36. Tenaillon MI, U'Ren J, Tenaillon O, Gaut BS: Selection versus demography: a multilocus investigation of the domestication process in maize. Mol Biol Evol 2004, 21:1214-1225.

37. Larsson SJ, Lipka AE, Buckler ES: Lessons from Dwarf8 on the Strengths and Weaknesses of Structured Association Mapping. PLoS Genetics 2013, 9:e1003246.

38. Morrell PL, Buckler ES, Ross-lbarra J: Crop genomics: advances and applications. Nat Rev Genet 2011, 13:85-96.

39. Yan J, Shah T, Warburton ML, Buckler ES, McMullen MD, Crouch J: Genetic characterization and linkage disequilibrium estimation of a global maize collection using SNP markers. PLoS One 2009, 4:e8451.

40. Van Inghelandt D, Melchinger AE, Lebreton C, Stich B: Population structure and genetic diversity in a commercial maize breeding program assessed with SSR and SNP markers. Theor Appl Genet 2010, 120:1289-1299.

41. Lu Y, Shah T, Hao Z, Taba S, Zhang S, Gao S, Liu J, Cao M, Wang J, Prakash AB, Rong T, Xu Y: Comparative SNP and haplotype analysis reveals a higher genetic diversity and rapider LD decay in tropical than temperate germplasm in maize. PLoS One 2011, 6:e24861.

42. Van Heerwaarden J, Hufford MB, Ross-lbarra J: Historical genomics of North American maize. Proc Natl Acad Sci USA 2012, 109:12420-12425.

43. Springer NM, Ying K, Fu Y, Ji T, Yeh C-T, Jia Y, Wu W, Richmond T, Kitzman J, Rosenbaum H, Iniquez AL, Barbazuk WB, Jeddeloh JA, Nettleton D, Schnable PS: Maize inbreds exhibit high levels of copy number variation (CNV) and presence/absence variation (PAV) in genome content. PLoS Genet 2009, 5:e1000734.

44. Lu F, Lipka A, Elshire R, Glaubitz J, Cherney J, Casler M, Buckler E, Costich D: Switchgrass genomic diversity, ploidy and evolution: novel insights from a network-based SNP discovery protocol. PLoS Genet 2013, 9:e1003215.

45. Clark AG, Hubisz MJ, Bustamante CD, Williamson SH, Nielsen R: Ascertainment bias in studies of human genome-wide polymorphism. Genome Res 2005, 15:1496-1502.

46. Gravel S, Henn BM, Gutenkunst RN, Indap AR, Marth GT, Clark AG, Yu F, Gibbs RA, Bustamante CD, Altshuler DL, Durbin RM, Abecasis GR, Bentley DR, Chakravarti A, Collins FS, De La Vega FM, Donnelly P, Egholm M, Flicek P, Gabriel SB, Knoppers BM, Lander ES, Lehrach H, Mardis ER, McVean GA, Nickerson DA, Peltonen L, Schafer AJ, Sherry ST, Wang J, et al: Demographic history and rare allele sharing among human populations. Proc Natl Acad Sci USA 2011, 108:11983-11988.

47. Reif JC, Hallauer AR, Melchinger AE: Heterosis and heterotic patterns in plants. Maydica 2005, 50:215-223.

48. Nelson PT, Coles ND, Holland JB, Bubeck DM, Smith S, Goodman MM: Molecular characterization of maize inbreds with expired U.S. plant variety protection. Crop Sci 2008, 48:1673-1686.

49. Mikel MA: Genetic composition of contemporary U.S. commercial dent corn germplasm. Crop Sci 2011, 51:592-599.

50. Goodman MM: Broadening the genetic diversity in maize breeding by use of exotic germplasm. In The Genetics and Exploitation of Heterosis in Crops Edited by: Coors JG, Pandey S Madison: ASA, CSSA 1999, 139-148.

51. Salhuana W, Pollak L: Latin American Maize Project (LAMP) and Germplasm Enhancement of Maize (GEM) project: generating useful breeding germplasm 1. Maydica 2006, 51:339-355.

52. Van Inghelandt D, Reif JC, Dhillon BS, Flament P, Melchinger AE: Extent and genome-wide distribution of linkage disequilibrium in commercial maize germplasm. Theor Appl Genet 2011, 123:11-20

53. Atwell $S$, Huang YS, Vilhjálmsson BJ, Willems G, Horton $M, L i ~ Y$, Meng $D$, Platt A, Tarone AM, Hu TT, Jiang R, Muliyati NW, Zhang X, Amer MA, Baxter I, Brachi B, Chory J, Dean C, Debieu M, De Meaux J, Ecker JR, Faure $N$, Kniskern JM, Jones JDG, Michael T, Nemri A, Roux F, Salt DE, Tang C, Todesco M, et al: Genome-wide association study of 107 
phenotypes in Arabidopsis thaliana inbred lines. Nature 2010, 465:627-631.

54. Zhao K, Tung C-W, Eizenga GC, Wright MH, Ali ML, Price AH, Norton GJ, Islam MR, Reynolds A, Mezey J, McClung AM, Bustamante CD, McCouch SR: Genome-wide association mapping reveals a rich genetic architecture of complex traits in Oryza sativa. Nat Commun 2011, 2:467.

55. Durand E, Bouchet $S$, Bertin P, Ressayre A, Jamin P, Charcosset A, Dillmann $C$, Tenaillon Ml: Flowering time in maize: linkage and epistasis at a major effect locus. Genetics 2012, 190:1547-1562.

56. Meng X, Muszynski MG, Danilevskaya ON: The FT-like ZCN8 Gene Functions as a Floral Activator and Is Involved in Photoperiod Sensitivity in Maize. The Plant cell 2011, 23:942-960.

57. Hansey CN, Johnson JM, Sekhon RS, Kaeppler SM, De Leon N: Genetic diversity of a maize association population with restricted phenology. Crop Sci 2011, 51:704-715.

58. Bradbury PJ, Zhang Z, Kroon DE, Casstevens TM, Ramdoss Y, Buckler ES: TASSEL: software for association mapping of complex traits in diverse samples. Bioinformatics 2007, 23:2633-2635.

59. Panzea.. [http://www.panzea.org].

60. Purcell S, Neale B, Todd-Brown K, Thomas L, Ferreira MAR, Bender D, Maller J, Sklar P, De Bakker PIW, Daly MJ, Sham PC: PLINK: a toolset for whole-genome association and population-based linkage analysis. Am J Hum Genet 2007, 81:559-575.

61. Bastian M, Heymann S, Jacomy M: Gephi: an open source software for exploring and manipulating networks. AJS 2009, 2:361-362.

62. Venables WN, Ripley BD: Modern Applied Statistics with S. 4 edition. New York: Springer; 2002

63. Weir BS, Cockerham CC: Estimating F-Statistics for the analysis of population structure. Evolution 1984, 38:1358-1370.

64. Gilmour AR, Gogel BJ, Cullis BR, Thompson R: ASRemI User Guide Release 3.0 VSN International Ltd; 2009.

65. Lipka AE, Tian F, Wang Q, Peiffer J, Li M, Bradbury PJ, Gore MA, Buckler ES, Zhang Z: GAPIT: Genome Association and Prediction Integrated Tool. Bioinformatics 2012, 28:2397-2399.

66. Zhang Z, Ersoz E, Lai C-Q, Todhunter RJ, Tiwari HK, Gore MA, Bradbury PJ, Yu J, Arnett DK, Ordovas JM, Buckler ES: Mixed linear model approach adapted for genome-wide association studies. Nat Genet 2010, 42:355-360.

67. VanRaden P: Efficient methods to compute genomic predictions. J Dairy Sci 2008, 91:4414-4423.

doi:10.1186/gb-2013-14-6-r55

Cite this article as: Romay et al: Comprehensive genotyping of the USA national maize inbred seed bank. Genome Biology 2013 14:R55.

\section{Submit your next manuscript to BioMed Central and take full advantage of:}

- Convenient online submission

- Thorough peer review

- No space constraints or color figure charges

- Immediate publication on acceptance

- Inclusion in PubMed, CAS, Scopus and Google Scholar

- Research which is freely available for redistribution

Submit your manuscript at www.biomedcentral.com/submit
Ciomed Central 